\title{
The Importance of Chemical Activation and the Effect of Low Operation Voltage on the Performance of Pt-alloy Fuel Cell Electrocatalysts
}

Matija Gatalo ${ }^{\mathrm{a}, \mathrm{b}}$, Alejandro Martinez Bonastre ${ }^{\mathrm{c}, *}$, Leonard-Jean Moriau ${ }^{\mathrm{a}}$, Harriet Burdett ${ }^{\mathrm{c}}$, Francisco Ruiz-Zepeda ${ }^{a}$, Edwin Hughes ${ }^{c}$, Adam Hodgkinson ${ }^{d}$, Martin Šala ${ }^{\mathrm{e}}$, Luka Pavko ${ }^{\mathrm{a}}$, Marjan Bele ${ }^{\mathrm{a}}$, Nejc Hodnik ${ }^{\mathrm{a}, \mathrm{f}, *}$, Jonathan Sharman ${ }^{\mathrm{c}}$, Miran Gaberšček ${ }^{\mathrm{a}}$

a Department of Materials Chemistry, National Institute of Chemistry, Hajdrihova 19, 1000 Ljubljana, Slovenia

${ }^{\mathrm{b}}$ ReCatalyst d.o.o., Hajdrihova 19, 1000 Ljubljana, Slovenia

c Johnson Matthey Technology Centre, Blount's Court, Sonning Common, Reading, RG4 9NH, UK

d Johnson Matthey Fuel Cells, Lydiard Fields, Great Western Way, Swindon SN5 8AT, UK

e Department of Analytical Chemistry, National Institute of Chemistry, Hajdrihova 19, 1000 Ljubljana, Slovenia

${ }^{\mathrm{f}}$ University of Nova Gorica, 5000 Nova Gorica, Slovenia

* to whom correspondence should be addressed: Alex.Martinez.Bonastre@matthey.com, nejc.hodnik@ki.si.

\section{Keywords}

Platinum-alloys (Pt-M), chemical activation, de-alloying, proton exchange membrane fuel cells (PEMFC), oxygen reduction reaction (ORR), lower voltage limit (LVL). 


\section{ABSTRACT}

Pt-alloy (Pt-M) nanoparticles (NPs) with less expensive 3d transition metals ( $\mathrm{M}=\mathrm{Ni}, \mathrm{Cu}, \mathrm{Co})$ supported on high surface area carbon supports, are currently the state-of-the-art (SoA) solution to reach the production phase in proton exchange membrane fuel cells (PEMFCs). However, while Pt-M electrocatalysts show promise in terms of increased activity for oxygen reduction reaction (ORR) and thus, cost reductions from a significantly lower use of expensive and rare $\mathrm{Pt}$, key challenges in terms of synthesis, activation and stability remain to unlock their true potential. This work systematically tackles them with a combination of electrocatalyst synthesis and characterization methodologies including thin-film rotating disc electrodes (TF$\mathrm{RDE}$ ), an electrochemical flow cell linked to an inductively coupled plasma mass spectrometer (EFC-ICP-MS) and testing in $50 \mathrm{~cm}^{2}$ membrane electrode assemblies (MEAs). In the first part of the present work, we highlight the crucial importance of the chemical activation (dealloying) step on the performance of Pt-M electrocatalysts in the MEA at high current densities (HCDs). In addition, we provide the scientific community a preliminary and facile method of distinguishing between a 'poorly' or 'adequately' de-alloyed (activated) Pt-alloy electrocatalyst using a much simpler and affordable TF-RDE methodology using the wellknown CO-stripping. Since the transition metal cations can also be introduced in a PEMFC due to the degradation of the Pt-M NPs, the second part of the work focuses on presenting clear evidence on the direct impact of the lower voltage limit (LVL) on the stability of Pt-M electrocatalysts. The data suggests that in addition to intrinsic improvements in stability, significant improvements in the PEMFC lifetime can also be obtained via correct MEA design and applied limits of operation, namely restricting not just upper but equally important also lower operation voltage. 


\section{INTRODUCTION}

Electrification of the transport sector and the transition towards renewable energy solutions is crucial in the race towards cutting the greenhouse gas emissions. While battery electric vehicles are already leading the way, an important part of the electrification puzzle will be fuel cell electric vehicles ${ }^{1}$. One of the main barriers preventing mass adoption of proton exchange membrane fuel cell (PEMFC) technology remains the high-cost of the electrocatalyst material ${ }^{2}$. Due to the inherently sluggish oxygen reduction reaction (ORR), a large amount of platinum $(\mathrm{Pt})$ is required, which would represent over $50 \%$ of the total membrane electrode assembly (MEA) manufacturing costs ${ }^{3}$ making it also the highest cost contributor to the entire stack ${ }^{4}$. In addition, $\mathrm{Pt}$ is a low earth abundancy, expensive critical raw material, which is limited in supply. In order to achieve significant cost reductions the amount of Pt in the cathode electrocatalyst must be reduced. High activity, high electrochemically active surface area (ECSA) as well as high durability are all necessary for achieving significant improvements ${ }^{5,6}$. While completely eliminating platinum group metals (PGMs) by the use of PGM-free electrocatalysts ${ }^{7}$ might seem a rational approach to reduce the costs, achieving sufficient power densities as well as durability of PGM-free electrocatalysts remain a major challenge with currently no clear solution in sight ${ }^{6,8-10}$. On the other hand, de-alloyed Pt-alloy (Pt-M) nanoparticles (NPs) with less expensive $3 \mathrm{~d}$ transition metals $(\mathrm{M}=\mathrm{Ni}, \mathrm{Cu}, \mathrm{Co})$ supported on high surface area carbon supports, are currently the state-of-the-art (SoA) solution to reach the production phase in PEMFCs ${ }^{11,12}$ - resulting from their facile and already at scale preparation. Cost reduction using Pt-alloys is possible due to two key features: (i) Pt-alloys dilute Pt-atoms inside the nanoparticle's core and thus improve Pt overall utilisation ${ }^{13-16}$ and (ii) they exhibit a higher kinetic activity towards the ORR due to a combination of a ligand, strain, coordination number and/or surface disorder effects ${ }^{17-23}$. This class of electrocatalysts has reached significant development as part of past Department of Energy (DoE) projects (in particularly de-alloyed $\mathrm{Pt}-\mathrm{Co} / \mathrm{C}$ and $\mathrm{Pt}-\mathrm{Ni} / \mathrm{C}$ electrocatalysts) ${ }^{24-26}$ and resulted in record in-MEA activities that exceed the DoE performance targets ${ }^{27}$ of $>0.44 \mathrm{~A} / \mathrm{mg}_{\mathrm{Pt}}$ with $<40 \%$ activity loss after $30 \mathrm{k}$ voltage cycles in the RDE and MEAs ${ }^{28}$. For this class of electrocatalysts, alloying is usually obtained via high-temperature thermal annealing ${ }^{29}$.

In addition to the importance of the bulk crystal structure of the Pt-alloy NPs, de-alloying (activation) step of the electrocatalyst also holds a crucial importance ${ }^{30,31}$. Relatively recently, transition metal cation (e.g. $\mathrm{Ni}, \mathrm{Co}, \mathrm{Cu}, \mathrm{Fe}, \ldots$ ) contamination in the PEMFC has been recognised as another probable major contributor towards poor HCD performance when using 
Pt-alloys ${ }^{32-35}$. On the other hand, certain transition metal cations were shown to diffuse into the membrane, causing formation of hydrogen peroxide radicals (due to the Fenton reaction ${ }^{36}$ ) that attack the membrane leading to failure of the PEMFC. Pt-Cu alloys have in the past shown severe durability issues due to proton starvation of the cathode as a result of $\mathrm{Cu}$ plating on to the anode Pt/C electrocatalyst and thus blocking the hydrogen oxidation reaction (HOR) ${ }^{37,38}$. Similar observations on the presence of $\mathrm{Cu}$ in the membrane and in the anode have been reported recently ${ }^{39}$. One possible solution to mitigate this has been demonstrated by P. Mani and co-workers ${ }^{40}$, where an already fabricated CCM was exposed to another round of acid washing. However, this solution is not suitable for any kind of mass production of MEAs. Thus, solutions are necessary on the level of catalyst production. Consequently, improved fundamental understanding of the influence of chemical activation (de-alloying) on the electrochemical behavior of Pt-alloy electrocatalysts is critical.

In addition to the possible introduction of transition metal cations in the MEA during the phases of electrocatalyst ink preparation and/or CCM fabrication, the leaching can also occur during the break-in procedures and/or because of the Pt-M electrocatalysts degradation that results in metal dissolution ${ }^{41}$. However, on the topic of metal dissolution, not only the intrinsic properties of an electrocatalyst material, but also the operational conditions of the PEMFC seem to play a crucial role. There is important evidence in the literature that highlight the significance of both the upper voltage limit (UVL), as well as the lower voltage limit (LVL) at limiting the degradation of Pt-based carbon supported electrocatalysts in the PEMFC. For instance, Uchimura and co-workers ${ }^{42}$ showed that ECSA loss increases when LVL is reduced from $0.8 \mathrm{~V}$ to $0.6 \mathrm{~V}$ when performing accelerated degradation test cycles while using a fixed UVL $(0.95 \mathrm{~V})$. At that time, the transient nature of Pt dissolution has not been fully understood and thus, the mechanistic interpretation of the increased degradation has not yet considered significant Pt dissolution arising from the de-stabilisation of the Pt-oxide species. This has been changed with the introduction of coupling methodologies between electrochemical cells and an inductively coupled plasma mass spectrometer (ICP-MS) that enabled time-and-potential resolved monitoring of dissolution of metals. ${ }^{43-46}$ The investigations revealed a significant link between Pt-dissolution and cathodically reduced Pt-oxide resulting from the so-called oxideplace exchange mechanism. ${ }^{43}$ Lastly, Yoshida and co-workers ${ }^{47}$ affirmed already during the launch of the $1^{\text {st }}$ generation Toyota Mirai the importance of limiting both the UVL and LVL to increase the fuel cell lifetime. This has been later confirmed during the investigation of the $1^{\text {st }}$ generation Toyota Mirai stack as part of the Department of Energy (DoE) Mirai Fuel Cell Vehicle report, revealing system-level limitations on the LVL of the stack ${ }^{48}$. While high UVLs 
occurring during the start-up/shut-down of the PEMFC lead to severe carbon corrosion ${ }^{49}$, the LVL seems to also play a significant role that is perhaps in particular importance for the successful implementation of Pt-alloys. For this reason further fundamental insights are necessary to truly understand this phenomenon.

Thus, in the present work, particular attention was given to the effect of the de-alloying (activation) step on the performance with TF-RDEs and in $50 \mathrm{~cm}^{2}$ MEAs in single-cells under a range of conditions. Furthermore, an additional link is established that connects the dealloying step with the observed TF-RDE features, in-line metal dissolution trends (using electrochemical flow cell (EFC) coupled to an inductively coupled plasma mass spectrometer (ICP-MS)) and corresponding single-cell performances. In addition, the effect of the LVL on the stability of Pt-alloys towards the dissolution of the less noble metal was investigated by a combination of both in-line metal dissolution measurements and accelerated degradation tests (ADT) in $50 \mathrm{~cm}^{2}$ single-cell data.

\section{EXPERIMENTAL}

\section{Synthesis of d-Pt-Cu/C-NIC and d-Pt-Ni/C-NIC electrocatalysts.}

The Pt-M ( $\mathrm{M}=\mathrm{Ni}$ or $\mathrm{Cu})$ electrocatalysts were prepared in accordance with the processes already reported previously. ${ }^{50,51}$ Briefly, the electrocatalysts have been prepared in three steps. In the first step, Pt NPs were deposited onto a commercial carbon black support (Ketjen Black EC300J) via double passivation galvanic displacement method reported elsewhere. ${ }^{50}$ In the second step, the prepared composites with deposited Pt NPs were thermally annealed in order to obtain an alloy crystal phase. In the last step, the electrocatalysts were subjected to two different activation (acid washing) protocols and thus, formation of a Pt-rich overlayer via dealloying. Within this study, Pt-rich overlayer should be understood that the top-most layers of the Pt-alloy NPs have a more Pt-rich chemical composition than the bulk of the Pt-alloy NPs. In other words, Pt-rich overlayer does not indicate an ideal 'core-shell' structure ${ }^{52}$ and still contains some of the less noble metal ${ }^{41}$. First protocol was performed in accordance to the work described previously ${ }^{30}$. Briefly, the process involves 4 times washing in $1 \mathrm{M}$ acetic acid under $\mathrm{CO}$ purge. These two electrocatalysts are denoted as d-Pt-Cu/C-NIC-A and d-Pt-Ni/CNIC-A and the activation protocol is denoted as S-activation. The second protocol involves 24 h washing in $0.5 \mathrm{M} \mathrm{H}_{2} \mathrm{SO}_{4}$ at $80{ }^{\circ} \mathrm{C}$. This protocol was developed during the previous $\mathrm{DoE}$ projects ${ }^{24-26}$. These two electrocatalysts are denoted as d-Pt-Cu/C-NIC-S and d-Pt-Ni/C-NIC$\mathrm{S}$ and the activation protocol is denoted as $\mathrm{S}$-activation. The results within this study are then 
compared to also activated d-Pt-Ni/C-JM benchmark with a similar metal loading provided by Johnson Matthey (JM).

\section{XRD analysis.}

The powder X-ray diffraction (XRD) measurements of all samples were carried out on a

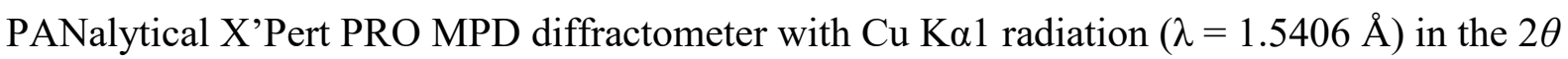
range from $10^{\circ}$ to $60^{\circ}$ with the $0.034^{\circ}$ step per $100 \mathrm{~s}$ using full opened $\mathrm{X}^{\prime}$ Celerator detector. Samples were prepared on zero-background Si holder.

\section{Transmission Electron Microscopy (TEM) analysis (NIC).}

STEM imaging was carried out in a probe Cs-corrected scanning transmission electron microscope Jeol ARM 200 CF operated at $80 \mathrm{kV}$.

\section{Transmission Electron Microscopy (TEM) analysis (JM).}

The samples were examined in the JEM 2800 (Scanning) Transmission Electron Microscope using the following instrumental conditions: Voltage (kV) 200.

\section{ICP-OES and digestion.}

All reagents used were of analytical grade or better. For sample dilution and preparation of standards, ultrapure water (18.2 $\mathrm{M} \Omega \mathrm{cm}^{-1}$, Milli-Q, Millipore) and ultrapure acids $\left(\mathrm{HNO}_{3}\right.$ and $\mathrm{HCl}$, Merck-Suprapur) were used. Standards were prepared in-house by dilution of certified, traceable, inductively coupled plasma (ICP)-grade single-element standards (Merck CertiPUR). A Varian 715-ES ICP optical emission spectrometer was used. Prior to ICP-OES analysis, each electrocatalyst was weighted (approximately $10 \mathrm{mg}$ ) and digested using a microwave-assisted digestion system (Milestone, Ethos 1) in a solution of $6 \mathrm{~mL} \mathrm{HCl}$ and $2 \mathrm{~mL}$ $\mathrm{HNO}_{3}$. Samples were then filtered, and the filter paper was again submitted to the same digestion protocol. These two times digested samples were cooled to RT and then diluted with $2 \% \mathrm{v} / \mathrm{v} \mathrm{HNO}_{3}$ until the concentration was within the desired concentration range.

\section{Electrochemical evaluation via Thin Film Rotating Disc Electrode (TF-RDE).}

Preparation of thin films and the setup - Electrochemical measurements were conducted with a CompactStat (Ivium Technologies) in a two-compartment electrochemical cell in a $0.1 \mathrm{M}$ $\mathrm{HClO}_{4}$ (Merck, Suprapur, $70 \%$, diluted by Milli-Q, $18.2 \mathrm{M} \Omega \mathrm{cm}$ ) electrolyte with a conventional three-electrode system. $\mathrm{Ag} \mid \mathrm{AgCl}$ was used as a reference and a graphite rod as a counter electrode. The working electrode was a glassy carbon disc embedded in Teflon (Pine Instruments) with a geometric surface area of $0.196 \mathrm{~cm}^{2}$. The $\mathrm{Ag} \mid \mathrm{AgCl}$ reference was separated 
from both the working and counter electrode with a salt bridge in order to avoid $\mathrm{Cl}^{-}$ions contamination. Prior to each experiment, the two-compartment electrochemical cell was boiled in Milli-Q water for 1 hour, and the electrode was polished to mirror finish with $\mathrm{Al}_{2} \mathrm{O}_{3}$ paste (particle size $0.05 \mu \mathrm{m}$, Buehler) on a polishing cloth (Buehler). After polishing, the electrodes were rinsed and ultrasonicated (Ultrasound bath Iskra Sonis 4) in Milli-Q/isopropanol mixture for $5 \mathrm{~min}$. $20 \mu \mathrm{L}$ of $1 \mathrm{mg} \mathrm{mL}^{-1}$ water-based well-dispersed electrocatalyst ink was pipetted on the glassy carbon electrode completely covering it and dried under ambient conditions. After the drop had dried, $5 \mu \mathrm{L}$ of Nafion solution (ElectroChem, $5 \%$ aqueous solution) diluted in isopropanol (1:50) was added. The electrode was then mounted on the rotator (Pine Instruments). The $\mathrm{Ag} \mid \mathrm{AgCl}$ reference electrode potential against $\mathrm{RHE}$ was determined before the start of the experiment.

Pt/C reference - In the case of Pt/C benchmark (TKK, TEC10E50E-HT) electrocatalyst measurements, the electrode was placed in an Ar saturated electrolyte under potential control at $0.05 \mathrm{~V}_{\mathrm{RHE}}$. The electrocatalyst was electrochemically activated (PCA) for 200 cycles between 0.05 and $1.2 \mathrm{~V}_{\mathrm{RHE}}$ with a scan rate of $300 \mathrm{mV} \mathrm{s}^{-1}$ at $600 \mathrm{rpm}$. After PCA, the electrolyte was exchanged with a fresh one and the electrode was no longer under any external potential control (i.e. the conditions corresponded to the open circuit potential - OCP). ORR polarization curves were measured in an oxygen saturated electrolyte at $1600 \mathrm{rpm}$ in the potential window 0.05-1.0 $\mathrm{V}_{\text {RHE }}$ with a scan rate of $20 \mathrm{mV} \mathrm{s}^{-1}$. Ohmic resistance of the electrolyte was determined and compensated for as reported in reference ${ }^{53}$. At the end of ORR polarization curve measurement, the electrolyte was purged with $\mathrm{CO}$ under potentiostatic mode $\left(0.05 \mathrm{~V}_{\mathrm{RHE}}\right)$ in order to ensure successful $\mathrm{CO}$ adsorption. Afterwards the electrolyte was saturated with Ar. CO-electrooxidation was performed using the same potential window and scan rate as in ORR, but without rotation and in an Ar saturated electrolyte. After subtraction of background current due to capacitive currents, kinetic parameters were calculated at $0.9 \mathrm{~V}_{\mathrm{RHE}}$ by using KouteckyLevich equation ${ }^{54}$. Electrochemically active surface area (ECSAco) was determined by integrating the charge in $\mathrm{CO}$ electrooxidation ('stripping') experiments as described in reference ${ }^{55}$. All potentials are given against the reversible hydrogen electrode (RHE), which was measured at the start of the experiment.

Pt-alloy electrocatalysts - The electrocatalysts were placed in the electrolyte without any potential control (at the OCP) in an oxygen saturated solution and ORR polarization curves were measured immediately after measurement of ohmic resistance and its compensation 
(under same conditions as in the case of $\mathrm{Pt} / \mathrm{C}$ benchmark electrocatalyst). The protocol for COelectrooxidation following the ORR measurement was the same as described above. At the end of CO-electrooxidation, 50 cycles of PCA $\left(0.05-1.2 \mathrm{~V}_{\mathrm{RHE}}, 300 \mathrm{mV} \mathrm{s}{ }^{-1}, 600 \mathrm{rpm}\right)$ were performed under the same parameters as in the case of $\mathrm{Pt} / \mathrm{C}$ benchmark electrocatalyst. Likewise, the electrolyte was exchanged with a fresh one at the end. ORR polarization curves and $\mathrm{CO}$-electrooxidation were measured once again under the same conditions as before PCA. Each Pt-alloy electrocatalyst was measured at least 3 times.

\section{Electrochemical Flow Cell Coupled to Inductively Coupled Plasma Mass Spectrometry (EFC-ICP-MS).}

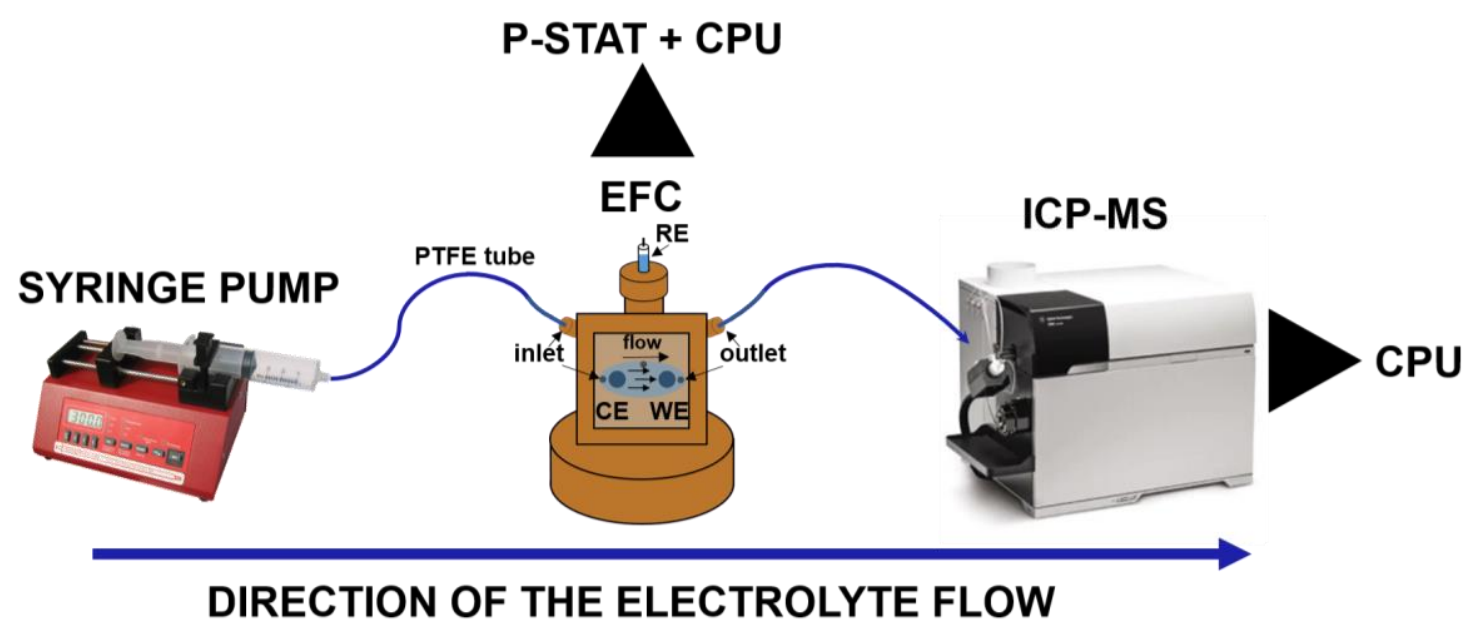

Scheme S1. EFC-ICP-MS setup used for obtaining time-and-potential resolved metal dissolution.

Electrochemical Flow Cell Setup - The setup and measurement guidelines were established as part of the previous work (Scheme 1) ${ }^{30,31,41,44,56-59}$. Briefly, the working and counter electrode in the electrochemical flow cell (EFC) were glassy carbon discs ( $3 \mathrm{~mm}$ diameter) embedded into PEEK material (BASi). The discs were aligned in series; the counter electrode was placed first and the working electrode second in the direction of the electrolyte flow. The sample was deposited on the electrode by drop casting $5 \mu \mathrm{L}$ drop of the ultrasonically homogenized catalyst ink $\left(1 \mathrm{mg} \mathrm{mL}^{-1}\right)$. Such preparation resulted in the electrocatalyst loading of $5 \mu \mathrm{g}$ for all electrocatalysts. In addition, in order to increase the surface area of the counter electrode, $5 \mu \mathrm{L}$ drop of Ketjen Black EC300J suspension $\left(1 \mathrm{mg} \mathrm{mL}^{-1}\right)$ was deposited on the glassy carbon counter electrode. After the drop had dried, $5 \mu \mathrm{L}$ of Nafion solution (ElectroChem, $5 \%$ aqueous solution) diluted in isopropanol (1:50) was added. The $\mathrm{Ag} \mid \mathrm{AgCl}$ reference electrode potential against RHE was determined before the start of the experiment. The housing of the cell was made from PEEK material and the design was modelled after a commercial cross-flow cell 
(BASi, MF-1092, cross-flow cell). The volume of the cell was established with a home-made silicon gasket with $1.0 \mathrm{~mm}$ thickness and $1.5 \mathrm{~cm}^{2}$ ellipsoidal cut. The carrier solution $(0.1 \mathrm{M}$ $\mathrm{HClO}_{4}$ ) was pumped through the cell at a constant flow of $400 \mu \mathrm{L} \mathrm{min}^{-1}$. Two glass syringes using Luer Lock connection to a PTFE tubing, two syringe pumps (WPI AL1000-220Z) and a diagonal 4-way flow valve (Idex, V-100D) were used to enable a continuous flow of the solution.

ICP-MS - The EFC was coupled with an ICP-MS detector, namely Agilent 7900ce ICP-MS instrument (Agilent Technologies, Palo Alto, CA), equipped with a MicroMist glass concentric nebulizer and a Peltier cooled Scott-type double-pass quartz spray chamber. A forward radiofrequency power of $1500 \mathrm{~W}$ was used with Ar gas flows: carrier $0.85 \mathrm{~L} \mathrm{~min}^{-1}$; makeup $0.28 \mathrm{~L}$ $\min ^{-1}$; plasma $1 \mathrm{~L} \mathrm{~min}^{-1}$; and cooling $15 \mathrm{~L} \mathrm{~min}^{-1}$. The signals were recorded for $\mathrm{Cu}^{63}, \mathrm{Ni}^{60}$ and $\mathrm{Pt}^{195}$ with $0.5 \mathrm{~s}$ integration per data point. To convert the ICP-MS signals to concentration (ppb), standard solution of $\mathrm{Cu}, \mathrm{Ni}$ and $\mathrm{Pt}$ in $0.1 \mathrm{M} \mathrm{HClO}_{4}$ were recorded with the following concentrations: $0.5,1,2,5,10,20,50$ and $100 \mathrm{ppb}$.

Electrochemical protocol - Electrochemical experiments were performed with a CompactStat (Ivium Technologies) with a typical three-electrode setup. No ohmic drop compensation method was used. The general electrochemical protocol is presented in SI, Figure S1. Initially, Milli-Q water was pumped through the cell under open circuit conditions (OCP) before switching to $0.1 \mathrm{M} \mathrm{HClO}_{4}$. After $10 \mathrm{~min}$ of acid flow, the potentiodynamic protocol was started; in order to check for the effect of the lower potential limit, the electrocatalysts were cycled for 3 cycles between $0.925-0 . X \mathrm{~V}_{\mathrm{RHE}}(\mathrm{X}=0.7,0.65$ and 0.6 ) with 9 cycles in total (scan rate of $5 \mathrm{mV} \mathrm{s}^{-1}$ ). In another set of experiments, "memory effect" was checked by omitting $\mathrm{X}$ $=0.7$ and 0.65 and only performing 3 cycles between $0.925-0.6 \mathrm{~V}_{\mathrm{RHE}}$. In both cases, the experiment was followed with two cycles between 0.05-1.4 $\mathrm{V}_{\mathrm{RHE}}\left(\mathrm{scan}\right.$ rate of $5 \mathrm{mV} \mathrm{s}^{-1}$ ). After each experiment, a sequence of potential pulses (see SI, Figure S2) was performed in order to synchronise the electrochemical experiment with the ICP-MS signal. Briefly, at the end of the experiment, the system is left at OCP for 200 seconds for the MS signal to reach background levels. This is followed by applying the first potential (oxidative) 'pulse' (for $0.5 \mathrm{~s}$ ) till 1.4 $\mathrm{V}_{\text {RHE. }}$ After additional 150 seconds of waiting at OCP, a second potential (reductive) 'pulse' (for $0.5 \mathrm{~s}$ ) of $0.05 \mathrm{~V}_{\mathrm{RHE}}$ is applied. Both pulses result in significant dissolution in the ICP-MS data and enabling one to observe the time difference between the electrochemical pulse and the detection of the metal dissolution on the MS. 


\section{Single-cell (MEA) testing.}

MEA fabrication - The MEAs used in this work consist of five layers. Nafion 1100EW (equivalent weight in $\mathrm{g}$ polymer/mol $\mathrm{H}+$ ) was used to fabricate thin-layer electrodes. The cathode catalyst layers were prepared at an ionomer/carbon weight ratio of ca. 0.9 and metal loadings of ca. $0.10 \mathrm{mg}_{\mathrm{Pt}} \mathrm{cm}^{-2}$, unless specified otherwise. The anode catalyst layer was kept constant at an ionomer/carbon weight ratio of ca. 1.5/1 and a metal loading of $0.1 \mathrm{mg}_{\mathrm{Pt}} \mathrm{cm}^{-2}$. The membrane used was a perfluorosulfonic acid type, fabricated at JMFC with a thickness of ca. $20 \mu \mathrm{m}$. Catalyst layers were produced on a PTFE substrate and transferred via a decal method onto the membrane. Single cells $\left(50 \mathrm{~cm}^{2}\right.$ active area) were assembled by sandwiching the catalyst coated membranes between the GDLs and applying an average compression onto the active area.

Fuel cell testing - The fuel cell station was built in-house at JMFC. Pure oxygen and synthetic air were used as cathode reactants and pure $\mathrm{H}_{2}$ as the anode reactant (all gases of $99.9 \%$ purity). Stoichiometric flow rates of anode $(\mathrm{s}=2)$ and cathode $\left(\mathrm{s}=9.5\right.$ for $\mathrm{O}_{2}$ and $\mathrm{s}=2$ for air) reactants were used at current densities $>0.2 \mathrm{~A} \mathrm{~cm}^{-2}$ and constant flows (corresponding to $0.2 \mathrm{~A} \mathrm{~cm}^{-2}$ flows) at $<0.2 \mathrm{~A} \mathrm{~cm}^{-2}$. Reactant humidification was achieved by water-bubblers, the temperatures of which were calibrated to yield the desired relative humidity $(\mathrm{RH})$ values. Humidity and cell pressure were measured at the inlet for both electrodes. Cell resistances as a function of current density (i.e., the sum of the proton-conduction resistance in the membrane and the various electronic resistances, bulk and contact resistances) were determined using Hioki at $1 \mathrm{kHz}$. Multiple-path serpentine flow-fields (two and three parallel channels for the anode and cathode, respectively) machined into sealed graphite blocks were used for testing.

The MEAs were conditioned by the application of a constant current density of $500 \mathrm{~mA}$ $\mathrm{cm}^{-2}$ under $\mathrm{H}_{2} /$ Air at $50 \mathrm{kPa}$ gauge, $100 \% \mathrm{RH}$ and $80{ }^{\circ} \mathrm{C}$. The cell voltage was monitored until a stable value was observed. The conditioning step lasted $2 \mathrm{~h}$ unless specified otherwise. Afterwards the cathode catalyst layer was exposed to a series of cathode starvation steps (see below) followed by $2 \mathrm{~h}$ current hold at $500 \mathrm{~mA} \mathrm{~cm}^{-2}$ until a stable voltage was observed. After the starvation steps the MEA was ready for testing by a series of $\mathrm{H}_{2} / \mathrm{O}_{2}$ polarization curves for mass activity (MA) quantification at different stages of the protocol (50 kPa gauge, $100 \% \mathrm{RH}$ and $80{ }^{\circ} \mathrm{C}$ ). The polarization curves were recorded from low (i.e. $0.05 \mathrm{~A} \mathrm{~cm}^{-2}$ ) to high current (i.e. $2 \mathrm{~A} \mathrm{~cm}^{-2}$ ) ascending direction and backwards, descending direction. The current density was maintained for 3 minutes at each step and the MA value was obtained from the ascending 
polarization curve at $0.9 \mathrm{~V}$ by extrapolation resistance corrected. $\mathrm{H}_{2}$-crossover current densities were measured using the procedure described by Kocha et al ${ }^{60}$. In this test the hydrogen that permeates through the membrane to the cathode is oxidized by the application of a voltage (typically 250-300 $\mathrm{mV}$ are sufficient, and the last one above $400 \mathrm{mV}$ is in the mass transport limit) and the resulting current measured. Therefore, the cell was operated under $\mathrm{H}_{2} / \mathrm{N}_{2}$ and the gas crossover measurements were done at each of the operating conditions (i.e., temperature and $\mathrm{H}_{2}$-partial pressure). The catalyst activities were evaluated based on $\mathrm{H}_{2}$-crossover corrected current densities, $\mathrm{i}_{\text {eff }}\left(\right.$ i.e., $\mathrm{i}_{\mathrm{eff}}=\mathrm{i}+\mathrm{ix}$, with ix being on the order of 2-5 $\mathrm{A} \mathrm{cm}^{-2}$ ). MA reported in this article were not corrected for $\mathrm{H}_{2}$-crossover because the measured crossover currents accounted for a maximum of $10 \%$ at the loadings used in this study.

The ECSA was measured with the CO stripping method using the cell in half cell mode where the anode electrode acts as a pseudo reference electrode. The cathode voltage was controlled at $0.125 \mathrm{~V}$ at $80^{\circ} \mathrm{C}, 100 \% \mathrm{RH}$ and $50 \mathrm{kPa}$ gauge whilst purging with $1 \% \mathrm{CO}$ in $\mathrm{N}_{2}$ at $300 \mathrm{ml} \mathrm{min}^{-1}$ for $15 \mathrm{~min}$. Afterwards the cathode was purged with $\mathrm{N}_{2}$ at the same flow rate for $2 \mathrm{~h}$ to ensure that $\mathrm{CO}$ is removed from the bubblers and the catalyst layer pores. The adsorbed $\mathrm{CO}$ is oxidised electrochemically by scanning the cathode voltage from $0.125 \mathrm{~V}$ to $0.85 \mathrm{~V}$ and back to $0.05 \mathrm{~V}$, at $20 \mathrm{mV} \mathrm{s}^{-1}$ for three cycles. The area under the $\mathrm{CO}$ oxidation peak is integrated by subtracting the third scan from the first scan and using a $420 \mu \mathrm{C} \mathrm{cm}^{-2}$ constant for a $\mathrm{CO}$ monolayer on Pt.

For the voltage window experiments the benchmark d-Pt-Ni/C-JM cathode catalyst was tested for durability under $\mathrm{H}_{2} / \mathrm{N}_{2}$ with the UPL fixed at $0.925 \mathrm{~V}$ whilst the LVL was changed to $0.5,0.6$ or $0.7 \mathrm{~V}$. At both LVL and UVL, the voltage was held for 3 seconds whilst the rise time in between the voltage window of $(\mathrm{LVL}-0.925) \mathrm{V}$ was below $0.5 \mathrm{~s}$. The durability protocol was applied for a total of 1000 cycles, at $80^{\circ} \mathrm{C}, 100 \% \mathrm{RH}$ and ambient pressure at the cell outlet. Afterward, the cell voltage was measured at $1.2 \mathrm{~A} \mathrm{~cm}^{-2}$ at different temperatures as described in the text. 


\section{RESULTS AND DISCUSSION}

(a) Pt NP DEPOSITION

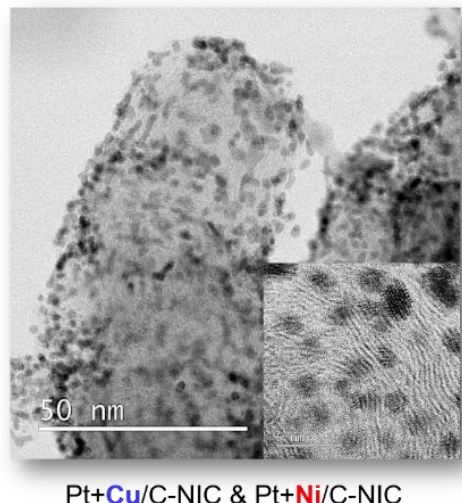

(d)

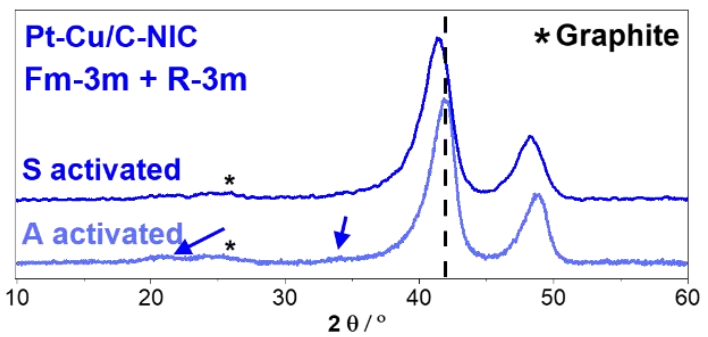

(b) THERMAL ANNEALING

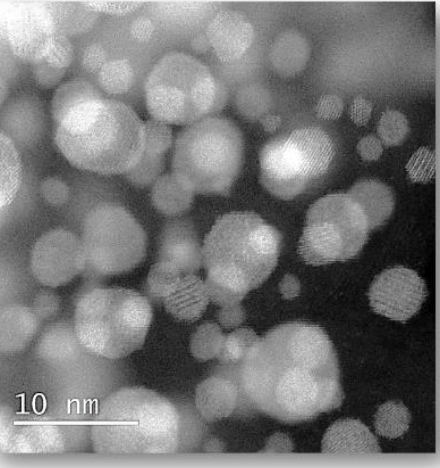

$\mathrm{Pt}-\mathrm{Cu} / \mathrm{C}-\mathrm{NIC} \& \mathrm{Pt}-\mathrm{Ni} / \mathrm{C}-\mathrm{NIC}$

(e) (c) CHEMICAL ACTIVATION

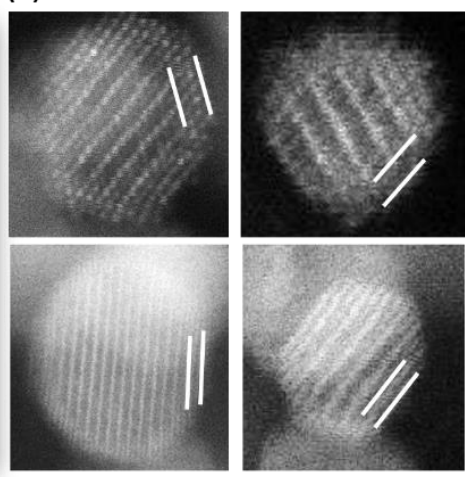

A-activation S-activation d-Pt-Cu/C-NIC-A d-Pt-Cu/C-NIC-S d-Pt-Ni/C-NIC-A d-Pt-Ni/C-NIC-S

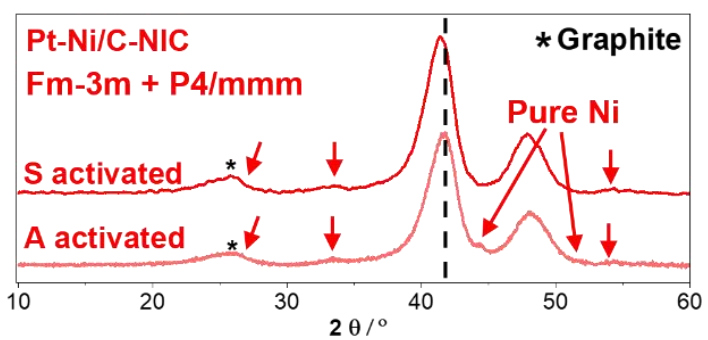

Figure 1. Three-step process used for preparation of Pt-M NIC electrocatalysts that involves (a) Pt NP deposition, (b) thermal annealing and (c) chemical activation (white lines indicate the Pt-rich overlayer). XRD analysis of (d) d-Pt-Cu/C-NIC (A-activated and S-activated) and (e) d-Pt-Ni/C-NIC (A-activated and S-activated) electrocatalysts. See also SI, Figures S3-5 for additional TEM characterization. Arrows indicate presence of a small fraction of the intermetallic phase or pure $\mathrm{M}$ phase.

The Pt-alloy NIC electrocatalysts were synthesized in a three-step process. In the first step (Figure 1a), Pt-based NPs were deposited on the M/C composites using our previously reported proprietary double passivation method. ${ }^{50,51}$ In the second step (Figure 1b), the obtained Pt-containing composites were subjected to a high-temperature thermal annealing in order to form a Pt-alloy structure ${ }^{29}$. In the last step (Figure 1c), for the purpose of this study, both Pt-M alloys $(\mathrm{M}=\mathrm{Cu}$ or $\mathrm{Ni}$ ) have been de-alloyed by using two different chemical activation (in other words acid washing) protocols. In one case, we have employed a rather mild previously reported de-alloying protocol $\left(4 \mathrm{x} 1 \mathrm{M}\right.$ acetic acid $\left.+\mathrm{CO}_{g}{ }^{30}\right)$ that uses mild conditions such as acetic acid, but in combination with an adsorptive gas such as $\mathrm{CO}_{g}$. The adsorptive gas binds to the Pt-surface and inhibits any possible re-adsorption of re-deposition of $\mathrm{M}$ ions ( $\mathrm{M}=\mathrm{Cu}$, Ni or possibly other less noble metals) onto Pt surface. This improves the ability to wash the de-alloyed $\mathrm{M}$ out of the carbon matrix during the process of acid washing 30. Hereinafter we will refer to this acid washing activation as protocol ' $A$ ' and the electrocatalysts d-Pt-Ni/C-NIC-A and d-Pt-Cu/C-NIC-A. On the other hand, the second de- 
alloying activation protocol included the use of a stronger acid such as sulfuric acid $\left(\mathrm{H}_{2} \mathrm{SO}_{4}\right)$ also reported by others as part of previous DoE projects $\left(0.5 \mathrm{M} \mathrm{H}_{2} \mathrm{SO}_{4}, 24\right.$ hours, $\left.80{ }^{\circ} \mathrm{C}\right){ }^{24-26}$. Hereinafter we will refer to this acid washing activation as protocol ' $\mathrm{S}$ ' and the electrocatalysts d-Pt-Ni/C-NIC-S and d-Pt-Cu/C-NIC-S. Furthermore, the results within this study are compared to the d-Pt-Ni/C-JM benchmark with a similar metal loading provided by Johnson Matthey (JM).

STEM observations of both de-alloyed Pt-alloy electrocatalysts (see SI, Figures S3-5) provide evidence of a very high loading and uniform density of NPs over the carbon support. Additionally, a closer inspection reveals the detailed structure of several NPs that include a Ptrich overlayer (Figure 1c; see also SI, Figures S3-5). In addition, the observed width of the main X-ray diffraction (XRD) peaks (Figures 1d,e) correlates well with the TEM characterization. Furthermore, whereas majority of observed Pt-M NPs in the present samples contain most likely the (disordered) Fm-3m crystal phase, a small fraction of the intermetallic (ordered) phase is also observed with both TEM and XRD. In the case of 'A-activated' Pt-Cu catalyst (Figure 1d), a small amount R-3m (rhombohedral) characteristic for the 1:1 (PtCu) ratio is observed ${ }^{61}$. On the other hand, A-activated Pt-Ni catalyst (Figure 1e) exhibits a small fraction of the tetragonal intermetallic crystal structure that is characteristic for the $1: 1(\mathrm{PtNi})$ ratio ${ }^{62}$. In addition, it exhibits some leftover pure Ni phase that is still present even after the mild A-activation protocol. In contrast, A-activated $\mathrm{Pt}-\mathrm{Cu}$ catalyst does not exhibit any pure $\mathrm{Cu}$ phase. Upon the exposure of both intermetallic catalysts to the harsher S-activation protocol we see two distinct changes in the case of S-activated Pt-Cu catalyst (Figure 1e). Firstly, the position of the most intense peaks at approximately $42^{\circ}$ and $49^{\circ}$ experienced a significant shift towards lower angles that correspond to a substantially more Pt-rich crystal structure. Secondly, any small fraction of the previously present superlattice peaks that correspond to the intermetallic phase disappeared into the background. This means that while the goal of the dealloying was to form a Pt-rich overlayer, the rather strong S-activation also affected the bulk properties of the intermetallic $\mathrm{Pt}-\mathrm{Cu}$ core and partly disordered the crystal structure to the point where the intermetallic phase is no longer visible under the used measurement conditions due to too small domain size ${ }^{30,63}$. On the other hand, the exposure of the Pt-Ni electrocatalyst to the harsher S-activation (Figure 1e) also resulted in the successful removal of the pure $\mathrm{Ni}$ phase. However, in contrast to the more $\mathrm{M}$ rich $\mathrm{Pt}-\mathrm{Cu}$ catalyst, the stronger S-activation did not significantly change the bulk composition of the Pt-Ni catalyst, resulting in only a very slight shift in the position of the most intensive XRD peaks. In addition, unlike in the case of 
$\mathrm{Pt}-\mathrm{Cu}$ (Figure 1d), the presence of a small fraction of the intermetallic phase for the Pt-Ni catalyst remained unchanged even after the harsher S-activation (Figure 1e).

Table 1. Comparison of ECSACo, SA and MA in liquid half-cell (TF-RDE). See also SI, Table S1 for metal contents and other parameters.

\begin{tabular}{|c|c|c|c|c|c|}
\hline Electrocatalyst & $\begin{array}{l}\mathrm{ECSA}_{\mathrm{CO}} \\
{\left[\mathrm{m}^{2} \mathrm{~g}_{\mathrm{Pt}}^{-1}\right]} \\
\end{array}$ & $\begin{array}{l}\text { SA@0.9V } \\
{\left[\mathrm{mA} \mathrm{cm}^{-2}\right]} \\
\end{array}$ & $\begin{array}{c}\text { MA@0.9V } \\
{\left[\mathrm{A} \mathrm{mg}_{\mathrm{Pt}}^{-1}\right]} \\
\end{array}$ & $\begin{array}{l}\mathrm{SA} @ 0.95 \mathrm{~V} \\
{\left[\mathrm{~mA} \mathrm{~cm} \mathrm{~cm}^{-2}\right]} \\
\end{array}$ & $\begin{array}{c}\mathrm{MA} @ 0.95 \mathrm{~V} \\
{\left[\mathrm{~A} \mathrm{mg}_{\mathrm{Pt}}^{-1}\right]} \\
\end{array}$ \\
\hline $\begin{array}{c}\mathrm{Pt} / \mathrm{C} \text { reference } \\
(\mathrm{TEC} 10 \mathrm{E} 50 \mathrm{E}-\mathrm{HT})\end{array}$ & 53.4 & 0.4 & 0.23 & 0.06 & 0.03 \\
\hline d-Pt-Ni/C-JM & $65+1$ & $1.92 \pm 0.21$ & $1.25 \pm 0.13$ & $0.21 \pm 0.02$ & $0.14 \pm 0.01$ \\
\hline d-Pt-Ni/C-NIC-A & $70 \pm 2$ & $1.46 \pm 0.01$ & $1.03 \pm 0.02$ & $0.20 \pm 0.02$ & $0.14 \pm 0.01$ \\
\hline d-Pt-Ni/C-NIC-S & $76 \pm 4$ & $1.30 \pm 0.08$ & $0.99 \pm 0.11$ & $0.15 \pm 0.01$ & $0.12 \pm 0.01$ \\
\hline $\mathrm{d}-\mathrm{Pt}-\mathrm{Cu} / \mathrm{C}-\mathrm{NIC}-\mathrm{S}$ & $77 \pm 2$ & $1.92 \pm 0.03$ & $1.48 \pm 0.15$ & $0.27 \pm 0.03$ & $0.23 \pm 0.06$ \\
\hline
\end{tabular}

Table 1 provides a comparison of liquid half-cell (thin-film rotating disc electrode; TFRDE) performance of the electrocatalysts used in this study. For all the electrocatalysts, the electrochemically active surface area was obtained by the integration of the COelectrooxidation $\left(\right.$ ECSA $\left._{\mathrm{CO}}\right)$ peak, while the kinetic performance for ORR was measured at both 0.9 as well as $0.95 \mathrm{~V}_{\mathrm{RHE}}$ (specific activity; SA and mass activity; MA). ${ }^{55}$ The liquid half-cell TF-RDE performance was evaluated in order to confirm the eligibility of the Pt-M NIC electrocatalysts for further investigation in $50 \mathrm{~cm}^{2}$ single-cells. This required the catalysts to exhibit a superior kinetic ORR performance in contrast to SoA Pt/C electrocatalysts ${ }^{64}$ as well as an ECSACO higher than at least $40 \mathrm{~m}^{2} \mathrm{~g}^{-1} \mathrm{Pt}^{5}$. According to expectations, the liquid half-cell TF-RDE kinetic performance of all Pt-M NIC catalysts at both 0.9 and $0.95 \mathrm{~V}_{\mathrm{RHE}}$ exceeds that of Pt/C from Tanaka Kikinzoku Kogyo (TEC10E50E-HT; see SI, Figure S6 for TEM characterization and Figure S7 for ORR polarization curve and CO-electrooxidation). In addition, the measured ORR performances are comparable or even exceed that of the d-PtNi/C-JM benchmark. Lastly, evaluation of ECSACo for all Pt-M NIC electrocatalysts also confirmed the suitability for further evaluation in single-cell measurements at JM testing facilities. 

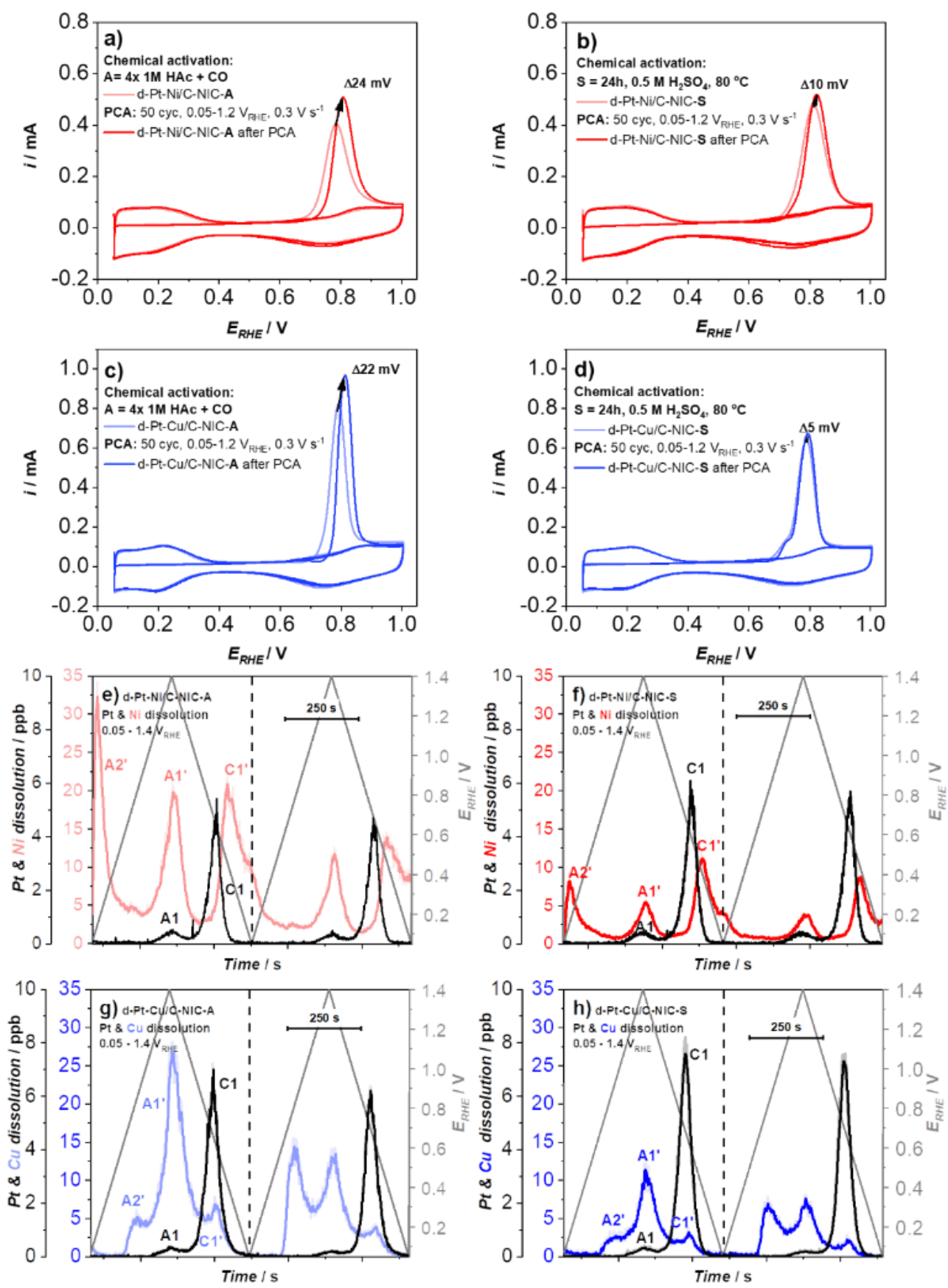

Figure 2: CO-electrooxidation comparison of measured in liquid electrolyte with TF-RDE for (a,c) d-Pt-M/C-NIC-A ( $\mathrm{M}=\mathrm{Ni}$ or $\mathrm{Cu})$ and $(\mathbf{b}, \mathbf{d}) \mathrm{d}-\mathrm{Pt}-\mathrm{M} / \mathrm{C}-\mathrm{NIC}-\mathrm{S}(\mathrm{M}=\mathrm{Ni}$ or $\mathrm{Cu})$ before and after additional 50 cycles of PCA $\left(0.1 \mathrm{M} \mathrm{HClO}_{4}, 0.05-1.2 \mathrm{~V}_{\mathrm{RHE}}, 300 \mathrm{mV} \mathrm{s}{ }^{-1}, 600 \mathrm{rpm}\right.$ rotation during activation and exchange of electrolyte prior at the end). $\mathrm{Pt}$ and $\mathrm{M}(\mathrm{M}=\mathrm{Ni}$ or $\mathrm{Cu})$ dissolution measured with EFC-ICP-MS in the flow of $0.1 \mathrm{M} \mathrm{HClO}_{4}(\mathrm{WPW}$; two cycles 0.05$1.4 \mathrm{~V}_{\mathrm{RHE}}, 5 \mathrm{mV} \mathrm{s}^{-1}$ ) for (e) d-Pt-Ni/C-NIC-A, (f) d-Pt-Ni/C-NIC-S, (g) d-Pt-Cu/C-NIC-A and (h) d-Pt-Cu/C-NIC-S.

Prior to the single-cell evaluation, a more in-depth analysis was conducted to provide a baseline understanding of the differences between A and S-activation protocols on both the liquid half-cell TF-RDE electrochemical properties as well as in-line metal dissolution (Figure 2; see also SI, Figures S8-10). In the case of TF-RDE measurements, both A- and S-activated 
catalysts were first evaluated by measuring ORR $\left(0.1 \mathrm{M} \mathrm{HClO}_{4}, 1600 \mathrm{rpm}, \mathrm{O}_{2}\right.$ saturated, iR corrected and background corrected, $\left.20 \mathrm{mV} \mathrm{s}^{-1}\right)$ followed by CO-electrooxidation $(0.1 \mathrm{M}$ $\mathrm{HClO}_{4}$, no rotation, Ar saturated, $20 \mathrm{mV} \mathrm{s}^{-1}$ ). This was then followed up by additional 50 electrochemical cycles of potential cycling activation (PCA; 0.05-1.2 $\mathrm{V}_{\mathrm{RHE}}, 300 \mathrm{mV} \mathrm{s}^{-1}, 0.1 \mathrm{M}$ $\mathrm{HClO}_{4}$ ). After PCA, ORR and $\mathrm{CO}$-electrooxidation were measured under the same conditions once again.

Figure 2a shows that in the case of d-Pt-Ni/C-NIC-A, upon additional de-alloying initiated via 50 cycles of PCA (0.05-1.2 $\left.\mathrm{V}_{\mathrm{RHE}}, 300 \mathrm{mV} \mathrm{s}^{-1}\right)$, the peak-maximum corresponding to CO-electrooxidation at approximately $0.8 \mathrm{~V}_{\mathrm{RHE}}$ shifts towards a more positive potential for $\sim 24 \mathrm{mV}$. However, for the case of more harshly activated d-Pt-Ni/C-NIC-S (Figure 2b), this potential shift reduces to only $10 \mathrm{mV}$. Despite the observed shift in CO-electrooxidation, there is interestingly no effect on the ORR polarization curves corresponding to their kinetic performances measured in half-cell TF-RDE before and after PCA for both A and S-activated catalysts respectively (see SI, Figures S8a and S8b). In addition, when comparing the $2^{\text {nd }}$ (start) and $50^{\text {th }}$ (end) cyclovoltammogram $(\mathrm{CV})$ of the PCA, a slight change in the distinct features corresponding to Pt-surface such as hydrogen underpotential deposition (HUPD) region and Pt-oxide formation and reduction regions can be observed (see SI, Figures S8c and S8d). When comparing the changes in these features for both $\mathrm{A}$ and S-activated catalysts respectively, unlike with the difference in the $\mathrm{CO}$-electrooxidation maximum shift, no major difference distinguishing both activation protocols is revealed. Interestingly, the exact same 10 $\mathrm{mV}$ difference in the CO-electrooxidation peak maximum before and after PCA has been observed in the case of the d-Pt-Ni/C-JM benchmark (see SI, Figure S9a). However, similarly to both A and S-activated Pt-Ni catalysts, PCA again had no effect on the ORR polarization curves corresponding to their kinetic performances measured in half-cell TF-RDE before and after PCA (see SI, Figures S9b). In addition, the changes in Pt-surface features when comparing the $2^{\text {nd }}$ (start) and $50^{\text {th }}$ (end) CV of the PCA are also similar (see SI, Figures S9c).

In order to confirm that the observed effects are not a feature of Pt-Ni alloy system, the exact same TF-RDE protocol was also performed on the d-Pt-Cu/C-NIC-A and d-Pt-Cu/CNIC-S electrocatalysts (Figures 2c-d). Intriguingly, the exact same trends are observed even in the case of a completely different Pt-alloy system. Once again, d-Pt-Cu/C-NIC-A experiences a significantly larger potential shift in CO-electrooxidation peak maximum measured before and after PCA (shift $=22 \mathrm{mV}$; Figure 2c) when compared to the S-activated catalyst (shift $=5 \mathrm{mV}$; Figure 2d). Furthermore, similarly to the Pt-Ni catalysts, ORR polarization curve comparison corresponding to the kinetic performances before and after PCA 
again reveals no visible difference for both $\mathrm{A}$ and $\mathrm{S}$-activated catalysts respectively (see SI, Figures S10a and S10b). Lastly, also the comparison of distinct features corresponding to the Pt-surface in the $2^{\text {nd }}$ and $50^{\text {th }}$ CV of the PCA (see SI, Figures S10c and S10d) reveals only slight changes for both A and S-activated Pt-Cu catalysts respectively. The take-away message here is that following our TF-RDE protocol, only a slight difference in the shift of the COelectrooxidation peak maximum provides a possible clue that the $\mathrm{A}$ and $\mathrm{S}$-activated catalysts could in-fact be quite different despite exhibiting a similar ORR activity in TF-RDE.

We can get the first confirmation of these differences by measuring the respective intrinsic metal dissolution profiles of activated Pt-alloy electrocatalysts using a wellestablished 41,44,56-59,65 highly sensitive method, namely electrochemical flow cell (EFC) coupled to an inductively coupled plasma mass spectrometer (ICP-MS). This advanced electrochemical characterization method allows us to track on-line time-and-potential-resolved dissolution of metals (Figures 2e-g; see also SI, Figure S9d). Other variations of the methodology used by other research groups, instead of the EFC, include usage of a scanning flow cell (SFC) ${ }^{45,66,67}$ or a variation used in combination with an RDE system ${ }^{68,69}$. The intrinsic metal dissolution was monitored in accordance with the protocol presented in Figure S1. Briefly, each Pt-alloy electrocatalyst was exposed to the open circuit potential conditions (I. OCP). This was followed by evaluation of the lower potential limit (II. LPL) effect (3 cycles each LPL, 0.925-0.X $\mathrm{V}_{\mathrm{RHE}}$; $\mathrm{X}=70 / 65 / 60,5 \mathrm{mV} \mathrm{s}^{-1}, 0.1 \mathrm{M} \mathrm{HClO}_{4}$ ) that will be presented in detail later on. Lastly, the LPL protocol was followed by 2 more wide potential window (III. WPW) cycles between $0.05 \mathrm{~V}_{\text {RHE }}$ and upper potential limit (UPL) of $1.4 \mathrm{~V}_{\text {RHE }}$ (also $5 \mathrm{mV} \mathrm{s}^{-1}$ ) to initiate substantial dissolution of $\mathrm{Pt}$ and consequently, also dissolution of the less noble metal. In other words, we wanted to probe how much of the less noble metal gets dissolved if we severely damage the "stable" Pt-rich surface. If parts II. and III. would be reversed, the WPW cycles (0.05-1.4 $\left.\mathrm{V}_{\mathrm{RHE}}\right)$ could already substantially deplete the intrinsically unstable less noble metal from the Pt-rich overlayer and highly affect the results of the LPL studies presented in the next chapter. This is because the quantities of metal dissolution are substantially higher when Pt-based electrocatalysts are exposed to a wider potential window ${ }^{31,67}$.

As observed in the case of WPW cycles (0.05-1.4 $\mathrm{V}_{\mathrm{RHE}}, 5 \mathrm{mV} \mathrm{s} \mathrm{m}^{-1}, 0.1 \mathrm{M} \mathrm{HClO}_{4}$; Figures 2e-g; see also SI, Figure S9d), one can expect two typical transient Pt dissolution peaks ${ }^{43-}$ 45,57,70-72. Usually, this includes a smaller peak corresponding to the anodic (A1) and a more dominant cathodic (C1) Pt dissolution. Anodic (A1) Pt dissolution mechanism involves surface structure roughening caused by oxide place exchange mechanism. ${ }^{43}$ This creates Pt defects (low coordination sites), which do not get passivated by oxide formation and are thus prone to 
dissolution ${ }^{45}$. On the other hand, with further penetration of oxygen in the crystal lattice of the NPs, reduction of this Pt-oxide results in formation of a much larger amount of unstable Pt defects, leading to a significant cathodic $(\mathrm{C} 1)$ dissolution ${ }^{43}$. Furthermore, what seems to be a general feature for all Pt-alloys ${ }^{41}$ is that following both the A1 and C1 Pt dissolution, we also observe A1' and C1' less noble metal dissolution. In other words, every time Pt dissolves, this exposes previously protected $\mathrm{M}$ atoms and causes their subsequent dissolution ${ }^{31}$. In addition to that, Pt-alloys usually also exhibit another peak related to the less noble metal dissolution (A2'). However, what is special in this case is that A2' does not have a corresponding Pt dissolution peak such as $\mathrm{A} 1$ ' and $\mathrm{C} 1$ '. For instance, A2' $\mathrm{Cu}$ dissolution peak (Pt-Cu alloy; Figures $\mathbf{2 h}$ and $\mathbf{g}$ ) is related to the desorption ('stripping') of $\mathrm{Cu}$ from the Pt surface ( $\left.\mathrm{Cu} \mathrm{uPD}_{\mathrm{UP}}\right)$ 30,31,37,38,41. On the other hand, the origin of A2' Ni dissolution peak (Pt-Ni alloy; Figures 2e and f; see also SI, Figure 9d) cannot be yet determined accurately. What we can presume, however, is that in both cases, the alloyed less noble metal is stable until Pt-oxide (or perhaps the less noble metal oxide) is reduced. ${ }^{73}$ In accordance to the protocol presented in Figure $\mathbf{S 1}$ of the SI, after the end of II. LPL, the electrocatalyst is briefly exposed to OCP conditions, followed by a jump to $0.05 \mathrm{~V}_{\mathrm{RHE}}$ (where the Pt-oxide gets reduced) and start of WPW cycles. While A2' Cu (Figures 2g-h) remains stable a bit further even in the metallic form due to its higher standard electrode potential, A2' Ni (Figures 2e-f; see also SI, Figure S9d) starts to dissolve already at the beginning of the cycle $\left(0.05 \mathrm{~V}_{\mathrm{RHE}}\right)$. Thus, we can claim that the A2' dissolution definitely occurs on the Pt-alloy NPs. Last but also important difference to note in relation to the WPW cycles $\left(0.05-1.4 \mathrm{~V}_{\mathrm{RHE}}, 5 \mathrm{mV} \mathrm{s}^{-1}, 0.1 \mathrm{M} \mathrm{HClO}_{4}\right.$; Figures $2 \mathbf{f}$ and $\mathbf{g}$; see also SI, Figure S9d) is comparing the differences in A1' and C1' dissolution intensities. While both d-Pt-Ni/C-NIC-S (Figure 2f) and the d-Pt-Ni/C-JM benchmark (see SI, Figure S9d) exhibit a higher intensity of $\mathrm{Cl}^{\prime} \mathrm{Ni}$ dissolution than $\mathrm{Al}^{\prime}$, the situation is reversed in the case of d-Pt$\mathrm{Cu}$ /C-NIC-S (Figure 2g). Partly this can be explained by the fact that during the cathodic scan, part of the dissolved $\mathrm{Cu}$ deposited back to the Pt-surface as $\mathrm{Cu}_{\mathrm{UPD}}$ and only gets stripped away during the next anodic scan, resulting in an increased A2' Cu dissolution peak in the next cycle (Figures 2h-g) ${ }^{30,31,41}$. Nevertheless, the A1' $\mathrm{Cu}$ dissolution in the case of Pt-Cu alloy is still significantly higher than that of Pt-Ni alloy, which is in accordance to our prior work ${ }^{41,74}$.

However, the comparison of the total dissolved amounts of the less noble metal during the WPW cycles for d-Pt-Ni/C-NIC-A (Figure 2e) and d-Pt-Ni/C-NIC-S catalysts (Figure 2f) reveals a significantly different amount of Ni dissolution out of Pt-Ni NPs. While the amount of dissolved Pt within each cycle is comparable for both catalysts (due to similar Pt loadings 
on the glassy-carbon electrodes), more harshly S-activated catalyst losses substantially less Ni within each WPW cycle. Analogously to the same CO-electrooxidation peak maximum shift behavior of the d-Pt-Ni/C-JM benchmark, the Ni dissolution once again resembles more the behavior of S-activated Pt-Ni NIC catalyst (see SI, Figure S9d). A slight difference most likely originates due to a slightly higher metal ( $\mathrm{Pt}$ and $\mathrm{Ni} w \mathrm{w} \%$ ) loadings in the case of $\mathrm{d}-\mathrm{Pt}-\mathrm{Ni} / \mathrm{C}$ NIC-S (see SI, Table S1). Analogously, also comparison of d-Pt-Cu/C-NIC-A (Figure 2g) and d-Pt-Cu/C-NIC-S catalysts (Figure $2 \mathbf{h}$ ) reveals a significantly higher amount of $\mathrm{Cu}$ dissolution out of Pt-Cu NPs in the case of A-activated catalyst.

Because single-cell testing is time consuming, requires relatively large amounts of the electrocatalyst (in contrast to TF-RDE) and is highly complex in nature (many parameters can influence performance), it is highly important to be able to have a preliminary and facile method of distinguishing between a 'poorly' or 'adequately' de-alloyed (activated) Pt-alloy electrocatalyst. Providing such a solution has been one of the core goals of this study. Namely, the data so far suggests that both A-activated analogues not only exhibited a larger shift in the potential of the CO-electrooxidation peak maximum (Figures 2a-d), but also experienced a higher amount of less noble metal dissolution (Figures 2e-h). Thus, based on the evidence presented in this study (as well as our previous reports ${ }^{30,31}$ ) we argue that the potential difference in the CO-electroxidation peak maximum can serve as a very simple and sensitive preliminary indicator that can help distinguish between a 'poorly' or 'adequately' de-alloyed (activated) Pt-alloy electrocatalyst. The effect of the less noble metal ions on the position of the CO-electrooxidation peak has already been explored on the $\mathrm{Pt} / \mathrm{C}$ electrocatalyst by Durst and co-workers ${ }^{75}$. In their study, they have spiked the electrolyte with different amounts of various metal ions and observed shifts in the position of the CO-electrooxidation peak towards more negative potentials. This occurs because less noble metal ions induce a more facile (hydr)oxide formation at the Pt surface in the double layer. Hydrated less noble metal cations are located between the inner and outer Helmholtz plane where they partially lose their hydration shell and come closer to the Pt surface, inducing increase in the $\mathrm{OH}_{\text {ad }}$ coverage that can cause the shift in the onset of CO-electrooxidation towards lower potentials ${ }^{75}$. Following this study, we have explored this on Pt-alloys as part of our previous work where also a more 'mild' electrochemical activation (potential hold activation) resulted in a shift of COelectrooxidation peak maximum towards lower potentials in comparison to a harsher one (potential cycling activation) ${ }^{30,31}$. However, the present study for the first time provides the necessary data that correlates this effect with 'real' electrocatalyst samples based on the used chemical activation protocol (A or S-activation). Thus, if our assumption are correct, a similar 
correlation should be observed when performances of A- and S-activated Pt-M NIC analogues are evaluated in the $50 \mathrm{~cm}^{2}$ single-cells.

Table 2. Comparison of kinetic performance at $0.9 \mathrm{~V}$, ECSACO and average high frequency resistances (HFR) in $50 \mathrm{~cm}^{2}$ single-cells of $\mathrm{A}$ and $\mathrm{S}$-activated Pt-Ni and Pt-Cu NIC catalysts as well as the benchmark d-Pt-Ni/C-JM.

\begin{tabular}{|c|c|c|c|c|c|c|c|}
\hline \multirow{2}{*}{ Electrocatalyst } & \multirow{2}{*}{$\begin{array}{l}\text { Pt loading } \\
{\left[\mu \mathrm{g}_{\mathrm{Pt}} \mathrm{cm}^{-2}\right]}\end{array}$} & \multirow{2}{*}{$\begin{array}{l}\mathrm{I} / \mathrm{C} \\
\text { ratio }\end{array}$} & \multirow{2}{*}{$\begin{array}{l}\mathrm{SA} @ 0.9 \mathrm{~V} \\
{\left[\mathrm{~mA} \mathrm{~cm}{ }^{-2}\right]}\end{array}$} & \multirow{2}{*}{ 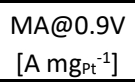 } & \multirow{2}{*}{$\begin{array}{c}\text { ECSAco } \\
{\left[\mathrm{m}^{2} \mathrm{~g}_{\mathrm{Pt}^{-1}}\right]}\end{array}$} & \multicolumn{2}{|c|}{$\mathrm{HFR}\left[\mathrm{m} \Omega \mathrm{cm}^{-2}\right]$} \\
\hline & & & & & & $100 \% \mathrm{RH}$ & $30 \% \mathrm{RH}$ \\
\hline d-Pt-Ni/C-JM & 99.6 & 0.9 & 1.00 & 0.53 & 55.3 & 48 & 61 \\
\hline d-Pt-Ni/C-NIC-A & 139 & 0.9 & 0.872 & 0.49 & 57 & 64 & 85 \\
\hline d-Pt-Ni/C-NIC-S & 81.7 & 0.9 & 1.07 & 0.51 & 68.7 & 52 & 65 \\
\hline d-Pt-Cu/C-NIC-A & 162 & 0.9 & 0.611 & 0.34 & 56 & 66 & 85 \\
\hline d-Pt-Cu/C-NIC-S & 88 & 0.9 & 0.903 & 0.56 & 64.3 & 56 & 76 \\
\hline
\end{tabular}

The comparison of kinetic performances (SA and MA at $0.9 \mathrm{~V}$ ) and ECSA $\mathrm{CO}$ (at $100 \%$ RH) for all investigated electrocatalysts in a $50 \mathrm{~cm}^{2}$ single-cell (MEA) is presented in Table 2. Under this study all electrocatalyst powders were treated under identical conditions during ink formulation (I/C ratio of 0.9) and all catalyst layers were printed and treated identically. As a result, it was observed, that the Pt cathode loading on A-activated analogues were higher than S-activated analogues. This is most likely due to different presences of transition metal cations in the catalyst inks that affected the ink viscosity. However, the mass activity results reported correct for the difference in Pt loading. First and foremost, it is interesting that despite d-Pt$\mathrm{Cu} / \mathrm{C}$-NIC-A being the most active electrocatalyst according to TF-RDE characterization (Table 1), it has the lowest MA among all the investigated electrocatalysts. This already suggests that presence of $\mathrm{Cu}$ ions in a single cell is significantly more damaging than $\mathrm{Ni}$ (similarly as $\mathrm{Co}^{38}$ ). On the other hand, the kinetic performance of d-Pt-Ni/C-NIC-A is also worse than that of the S-activated catalyst despite the trend being reversed in TF-RDE (Table 1). In addition, there is also a slight increase in ECSACO as a result of dissolved pure Ni phase upon exposure of the electrocatalyst to the S-activation protocol (Figure 1e). This trend is in good agreement with the ECSA evaluation by TF-RDE (Table 1). In contrast to A-activated catalysts, results of both S-activated Pt-alloys catalysts provide a similar kinetic performance at low current densities against the d-Pt-Ni/C-JM benchmark. Furthermore, with exception of d-Pt-Cu/C-NIC-A, the trends are in good agreement with the TF-RDE data (Table 1), where kinetic performances of S-activated electrocatalysts were also comparable to that of the d-PtNi/C-JM benchmark. 

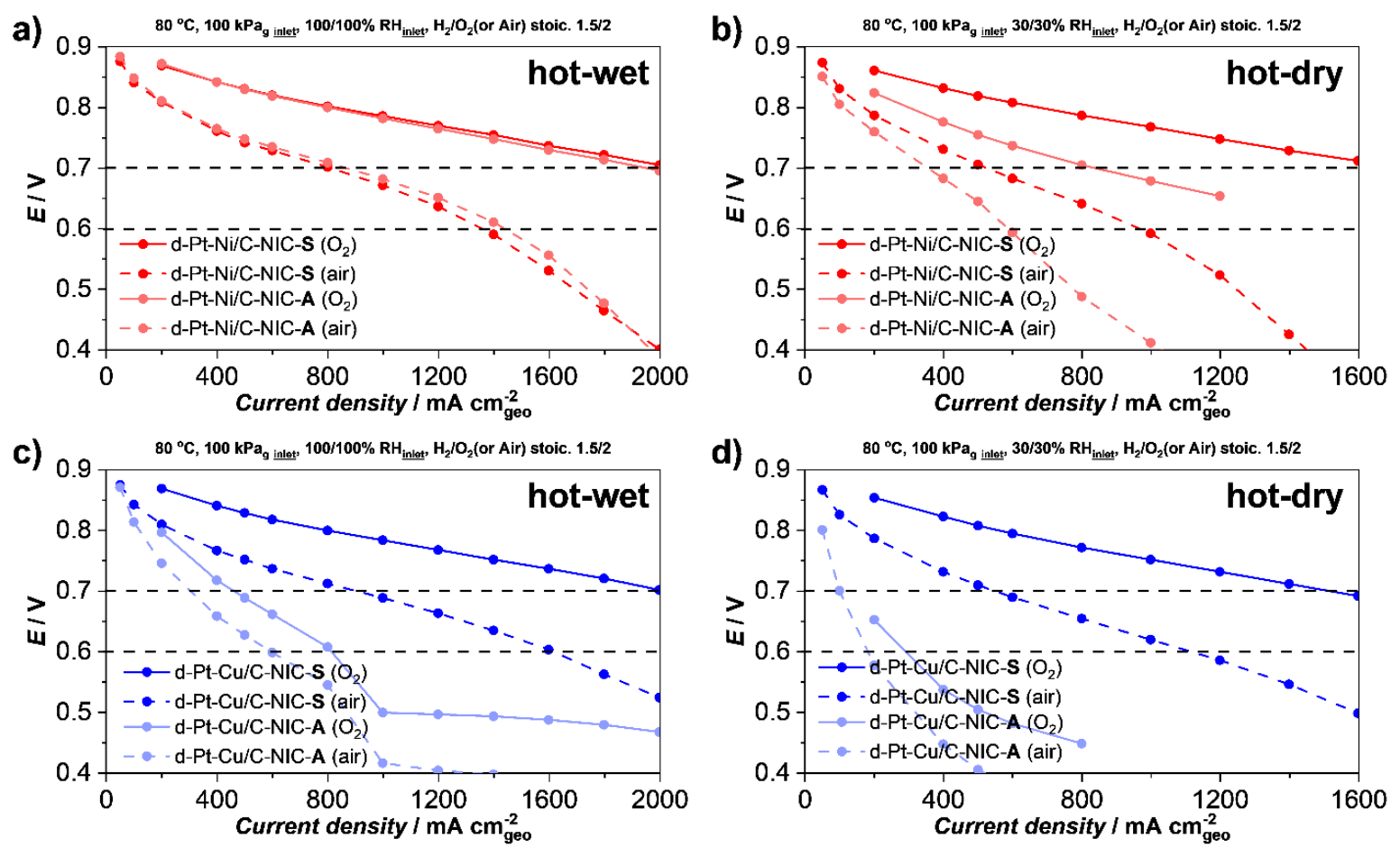

Figure 3. Comparison of ORR polarization curves measured in $50 \mathrm{~cm}^{2}$ single-cells under $\mathrm{H}_{2} / \mathrm{O}_{2}$ and $\mathrm{H}_{2} /$ Air (anode/cathode) using the Pt-alloy cathode catalysts shown in Table 2. General test conditions are specified in the figure. (a) Comparison of $\mathrm{A}$ and $\mathrm{S}$-activated Pt-Ni catalysts at hot-wet conditions $\left(80{ }^{\circ} \mathrm{C}, 100 \% \mathrm{RH}\right)$, (b) A and S-activated Pt-Ni catalysts at hot-dry conditions $\left(80{ }^{\circ} \mathrm{C}, 30 \% \mathrm{RH}\right),($ c) $\mathrm{A}$ and $\mathrm{S}$-activated $\mathrm{Pt}-\mathrm{Cu}$ catalysts at hot-wet conditions (80 $\left.{ }^{\circ} \mathrm{C}, 100 \% \mathrm{RH}\right)$ and (d) comparison of $\mathrm{A}$ and S-activated Pt-Cu catalysts at hot-dry conditions $\left(80{ }^{\circ} \mathrm{C}, 30 \% \mathrm{RH}\right)$. Single-cell ORR polarization data on d-Pt-Ni/C-JM electrocatalyst can be found in SI, Figure S11.

However, while kinetic performance that is comparable to the d-Pt-Ni/C-JM benchmark is already a good indication, it by far does not reveal the entire story. For that, we need to look at the $50 \mathrm{~cm}^{2}$ single-cell ORR polarization curves and thus, HCD performances at various conditions (Figure 3). Namely, both A and S-activated catalysts were compared in both $\mathrm{O}_{2}$ and air, as well as at both 'hot-wet' $\left(80^{\circ} \mathrm{C}, 100 \% \mathrm{RH}\right.$ on both the cathode and the anode) and 'hotdry' $\left(80{ }^{\circ} \mathrm{C}, 30 \% \mathrm{RH}\right.$ on both the cathode and the anode) conditions. Figure 3a shows the comparison of $50 \mathrm{~cm}^{2}$ single-cell ORR polarization curves between d-Pt-Ni/C-NIC-A and dPt-Ni/C-NIC-S electrocatalysts in 'hot-wet' conditions in both $\mathrm{O}_{2}$ and air. Interestingly, no significant difference is observed in $\mathrm{O}_{2}$ performance for both $\mathrm{A}$ and $\mathrm{S}$-activated catalysts up until $2 \mathrm{~A} \mathrm{~cm}^{-2}$ geo, whereas impressively, the voltage has not yet dropped below $0.7 \mathrm{~V}$. In contrast, in accordance to expectations, performance of both A and S-activated catalysts drops significantly when $\mathrm{O}_{2}$ on the cathode is exchanged for air. Nevertheless, both catalysts still achieve an impressive $1.4 \mathrm{~A} \mathrm{~cm}^{-2}$ geo at $0.6 \mathrm{~V}$ with the cathode loading of S-activated catalyst being only $\sim 82 \mu \mathrm{g}_{\mathrm{Pt}} \mathrm{cm}^{-2}$ (Table 2). Here we wish to emphasize to the reader that no effort was 
put into catalyst ink/layer optimization in the case of Pt-M NIC electrocatalysts as part of this study, but rather, these parameters were translated based on the previous work by JM ${ }^{34,76}$. Another important note here is that the observed difference between both A and S- activated Pt-Ni catalysts can be considered as experimental error or a result of a slightly different $\mathrm{Pt}$ cathode loadings (Table 2). Thus, these two performances can be considered as very similar. However, despite the similar performance of both A and S-activated Pt-Ni catalysts in 'hotwet' conditions, the same cannot be claimed when the 'hot-dry' conditions are used (Figure 3b). Here the d-Pt-Ni/C-NIC-S significantly outperforms d-Pt-Ni/C-NIC-A in both $\mathrm{O}_{2}$ and air. Looking now at both $\mathrm{A}$ and $\mathrm{S}$-activated $\mathrm{Pt}-\mathrm{Cu}$ catalysts, the differences become even more significant. Already upon comparison of the performances in 'hot-wet' conditions (Figure 3c), d-Pt-Cu/C-NIC-S significantly outperforms d-Pt-Cu/C-NIC-A. Interestingly, while the performance of approximately $2 \mathrm{~A} \mathrm{~cm}^{-2}$ geo at $0.7 \mathrm{~V}$ in $\mathrm{O}_{2}$ for the d-Pt-Cu/C-NIC-S is comparable to that of d-Pt-Ni/C-NIC-S, d-Pt-Cu/C-NIC-S achieves an impressive $1.6 \mathrm{~A} \mathrm{~cm}^{-2}$ geo at $0.6 \mathrm{~V}$ in air with a cathode loading of only $88 \mu \mathrm{g}_{\mathrm{Pt}} \mathrm{cm}^{-2}$. When we move into the 'hotdry' conditions (Figure 3d), similarly to both Pt-Ni catalysts, the performance of d-Pt-Cu/CNIC-A is once again much worse than that of d-Pt-Cu/C-NIC-S. However, while the HCD performance (air curves) of d-Pt-Cu/C-NIC-S exceeded that of d-Pt-Ni/C-NIC-S under the 'hot-wet' conditions (Figures 3a and 3c), the situation becomes reversed under the 'hot-dry' conditions (Figures 3b and 3d).

This mainly suggests three things: (i) Comparing Pt-alloy cathodes at both wet as well as dry conditions can reveal performance differences related to the presence of the less noble metal ions in the MEA. In particular, the present data also suggests that measuring only at wet conditions could even be misleading and mask transport issues related to the presence of less noble metal ions. Thus, measuring at lower (dryer) $\mathrm{RH}$ as well as in air rather than in $\mathrm{O}_{2}$ is critical for adequate evaluation of Pt-alloys, especially when considering and understanding the effects of the transition metal cations on the performance. (ii) 'Tolerance' for Ni ions in single-cells far exceeds that of $\mathrm{Cu}$ ions. When comparing both A-activated Pt-alloy catalysts at hot-wet conditions (Figures 3a and 3c), d-Pt-Ni/C-NIC-A exhibits significantly better BoL performance than d-Pt-Cu/C-NIC-A despite having even a small amount of pure-Ni phase (Figure 1e) that most likely, in addition to leaching of Ni from Pt-Ni NPs, additionally contributed towards additional contamination with $\mathrm{Ni}$ ions. However, transition metal ions can also be introduced in the MEA upon Pt-M electrocatalyst degradation. Thus, the second part of this work focuses on the effect of the LVL on the dissolution of the less noble metal from 
the Pt-M electrocatalysts. (iii) As predicted by the prior observations in TF-RDE and EFCICP-MS (Figure 2) S-activated Pt-M NIC analogues significantly outperformed the Aactivated ones in the $50 \mathrm{~cm}^{2}$ single cells, namely at the HCDs. This not only supports our arguments on the CO-electrooxidation shifts, but also suggests that the presence of the transition metal cations in the CCM is one of the most critical parameters governing the performance of Pt-alloys in PEMFCs. However, as already suggested, even if the Pt-alloy is 'adequately' activated and no significant amount of the less noble metal ions are introduced in the CCM at the BoL, due to aging of the Pt-M NPs, the operation of the PEMFC will overtime introduce fresh transition metal ions. Thus, in the second part of this study, the focus will be in understanding a highly underestimated parameter in PEMFC operation, the lower voltage limit (LVL).
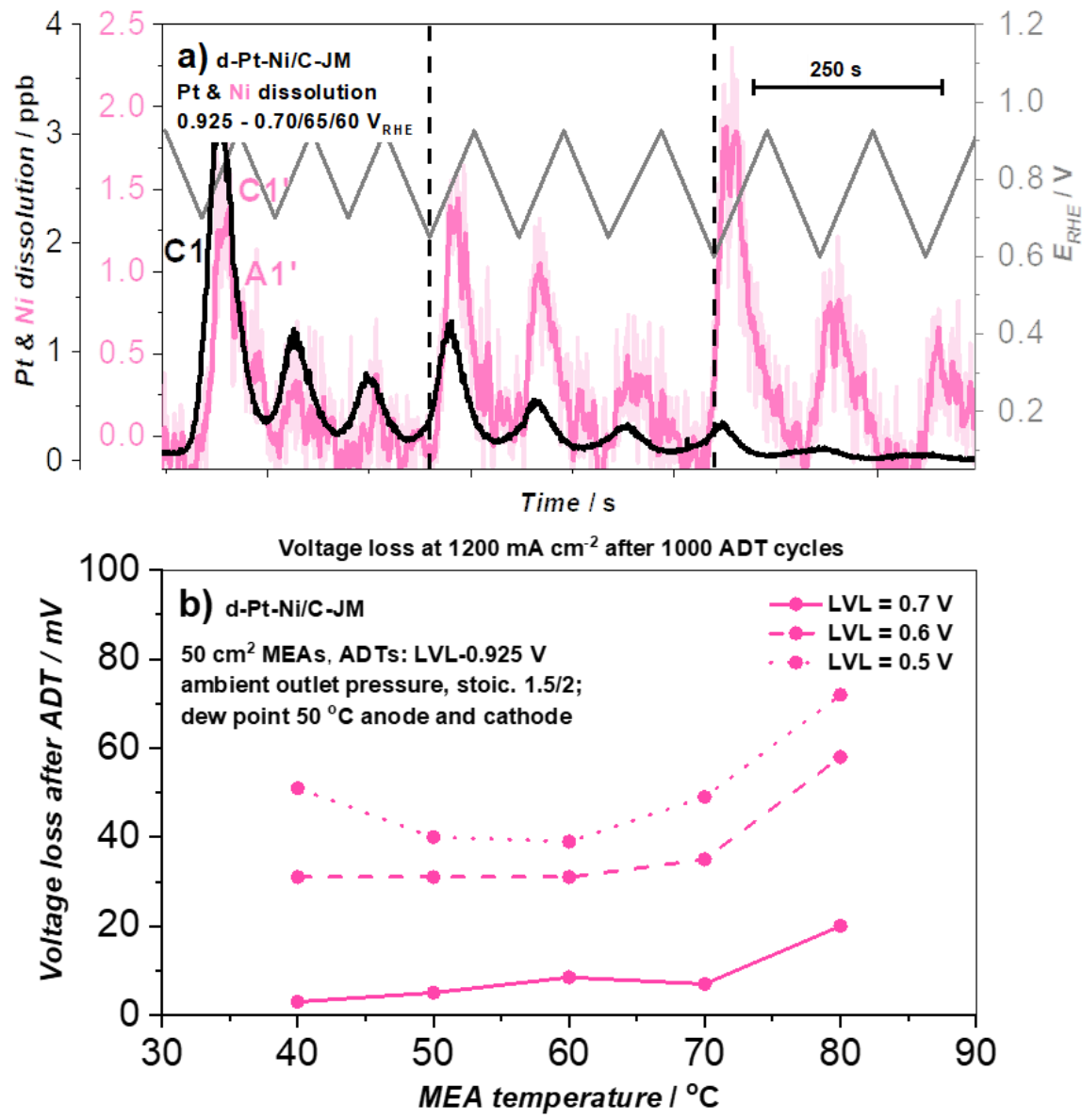

Figure 4. (a) $\mathrm{Pt}$ and $\mathrm{Ni}$ dissolution (LVL effect in operational voltage window; 0.925-0.X $\mathrm{V}_{\mathrm{RHE}} ; \mathrm{X}=0.70,0.65$ and $0.60 ; 5 \mathrm{mV} \mathrm{s}^{-1}$ ) for the d-Pt-JM/C-JM benchmark using EFC-ICPMS. See also SI, Figure S12 for reproducibility data and 'memory-effect' test. (b) Number of $\mathrm{mV}$ lost at $1200 \mathrm{~mA} \mathrm{~cm}^{-2}$ geo measured at different MEA temperatures after 1000 cycles of ADT using UPL of $0.925 \mathrm{~V}$ and different LVL values, namely $0.7,0.6$ and $0.5 \mathrm{~V}$ upon using the d$\mathrm{Pt}-\mathrm{Ni} / \mathrm{C}-\mathrm{JM}$ benchmark as the cathode catalyst (as shown in Table 2). 
The effect of the voltage window on Pt dissolution ${ }^{43-45,57,70-72}$ as well as on the dissolution of the less noble metal in the case of Pt-alloys ${ }^{30,31,65}$ is already well documented. However, most of the existing studies focus on the understanding of the changes in UPL of 1.0 $\mathrm{V}$ or above (in other words, understanding what happens if we $\mathrm{Pt}$ is more significantly oxidized). On the other hand, understanding the changes in LVL ${ }^{42}$, especially at UVLs below $1.0 \mathrm{~V}$, is perhaps similarly to the electrocatalyst activation, vastly underestimated and understudied ${ }^{65,72}$. Considering that the fuel cell stack will operate for the vast majority of its time within a voltage window of around (0.6-0.95) $\mathrm{V}$, understanding the mechanism of $\mathrm{Pt}$ and Pt-alloy degradation in this regime is in-fact critical.

Thus, we are hereby providing valuable evidence on the effect of lower potential limit (LPL) on metal dissolution by initially using the EFC-ICP-MS (3 cycles each LPL, 0.925-0.X $\mathrm{V}_{\mathrm{RHE}} ; \mathrm{X}=70 / 65 / 60,5 \mathrm{mV} \mathrm{s}^{-1}, 0.1 \mathrm{M} \mathrm{HClO}_{4}$ ) and evaluating all five Pt-alloy electrocatalysts from this study. The experimental protocol consists of in total 9 slow cycles with a scan rate of $5 \mathrm{mV} \mathrm{s}^{-1}$ in the operational potential window with a constant upper potential limit (UPL) and a decreasing LPL for $50 \mathrm{mV}$ every 3 cycles. Figure 4a shows the effect of lowering the LPL from 0.7 to $0.65 \mathrm{~V}$ as well as from 0.65 to $0.6 \mathrm{~V}_{\mathrm{RHE}}$ on the dissolution of both $\mathrm{Pt}$ and $\mathrm{Ni}$ in the case of the d-Pt-Ni/C-JM benchmark. Interestingly, while we have kept the UPL constant, lowering of the LPL results in an increase of Ni dissolution. Furthermore, we have tested this effect for reproducibility (see SI, Figures S12a and S12b) as well as excluded the possibility of a 'memory-effect'. Thus, in addition to the reproducibility measurements, where the initial LPL is $0.7 \mathrm{~V}_{\text {RHE }}$ (see SI, Figures S12c and S12d), we have performed two more measurements where the LPL of 0.6 $\mathrm{V}_{\text {RHE }}$ was used right away (see SI, Figures S12e and S12f). This way, no prior metal transient dissolution and thus, degradation took place prior to the 3 cycles with LPL of 0.6 V RHE. By going directly to the lowest LPL of $0.6 \mathrm{~V}$ (see SI, Figures S12e and S12f), the observed Ni dissolution was indeed substantially higher than in the case with LPL of $0.7 \mathrm{~V}_{\mathrm{RHE}}$ (see SI, Figures S12c and S12d).

To provide further evidence on this important phenomenon, we have extended our study by performing carefully designed accelerated degradation tests (ADTs) in $50 \mathrm{~cm}^{2}$ single-cells at various LVLs and temperatures using the d-Pt-Ni/C-JM benchmark as the cathode electrocatalyst. Figure $4 \mathbf{b}$ shows the decrease in $\mathrm{mV}$ at $1.2 \mathrm{~A} \mathrm{~cm}^{-2}$, in $50 \mathrm{~cm}^{2}$ single-cells, observed upon exposing the cathode catalyst layer to these ADTs (1000 cycles, 0.925-0.X $\mathrm{V}_{\mathrm{RHE}} ; \mathrm{X}=70 / 60 / 50,3$ second hold at both LVL and UVL; ambient outlet pressures, stoichiometry $1.5 / 2$, dew point $50{ }^{\circ} \mathrm{C}$ anode and cathode; $\mathrm{H}_{2} / \mathrm{N}_{2}$ ). The results clearly indicate that the highest voltage losses have been observed in the case of ADT conditions with LVL of 
$0.50 \mathrm{~V}_{\mathrm{RHE}}$, whereas the voltage losses decrease dramatically if the LVL is increased to 0.60 or $0.70 \mathrm{~V}_{\mathrm{RHE}}$ respectively. The trends presented in Figure $\mathbf{4 b}$ reveal another important parameter highly relevant for Pt-alloy cathodes. Regardless of the LVL used in the ADT (0.7, 0.6 or 0.5 $\mathrm{V})$, the observed cell voltage losses after the ADT significantly increase with temperatures above $60{ }^{\circ} \mathrm{C}$. This is, however, to be expected since temperature is also known to affect the kinetics of Pt-oxide formation and reduction, influencing the onsets ${ }^{71}$. Consequently, at the same LVL, a higher fraction of Pt-oxide gets reduced with increasing temperature, leading to a lower protection of the less noble metal towards the dissolution and thus, a higher voltage loss. Both the effects of the voltage window as well as the temperature are in line with our recent liquid electrolyte follow-up study ${ }^{74}$.

As further evidence on the importance of the results in the present study, revealing data published by Argonne National Laboratory ${ }^{48}$ with a detailed investigation of the operated Mirai stack showed that under system-controlled operation the voltage window was kept within the range (0.65-0.85) V. Analysis of MEAs showed no Co dissolution into the membrane under system-controlled operation, but that a large amount of Co had dissolved after the application of the ADT for catalyst durability defined by the US-DoE (0.60-0.95) V voltage window. The reported cathode loading for the Mirai MEAs under study were circa $0.30 \mathrm{mg}_{\mathrm{Pt}} \mathrm{cm}^{-2}$ and under the operating conditions used, this loading was enough to prevent exposure to aggressive upper and lower voltages (i.e. $<0.65$ or $>0.95 \mathrm{~V}$ ). It is plausible that this benign voltage window leads to low Pt dissolution and is probably one of the causes that prevented significant dissolution of cobalt. Clearly, this is a solid evidence that the voltage window used to determine the durability of Pt-alloys is extremely important. 

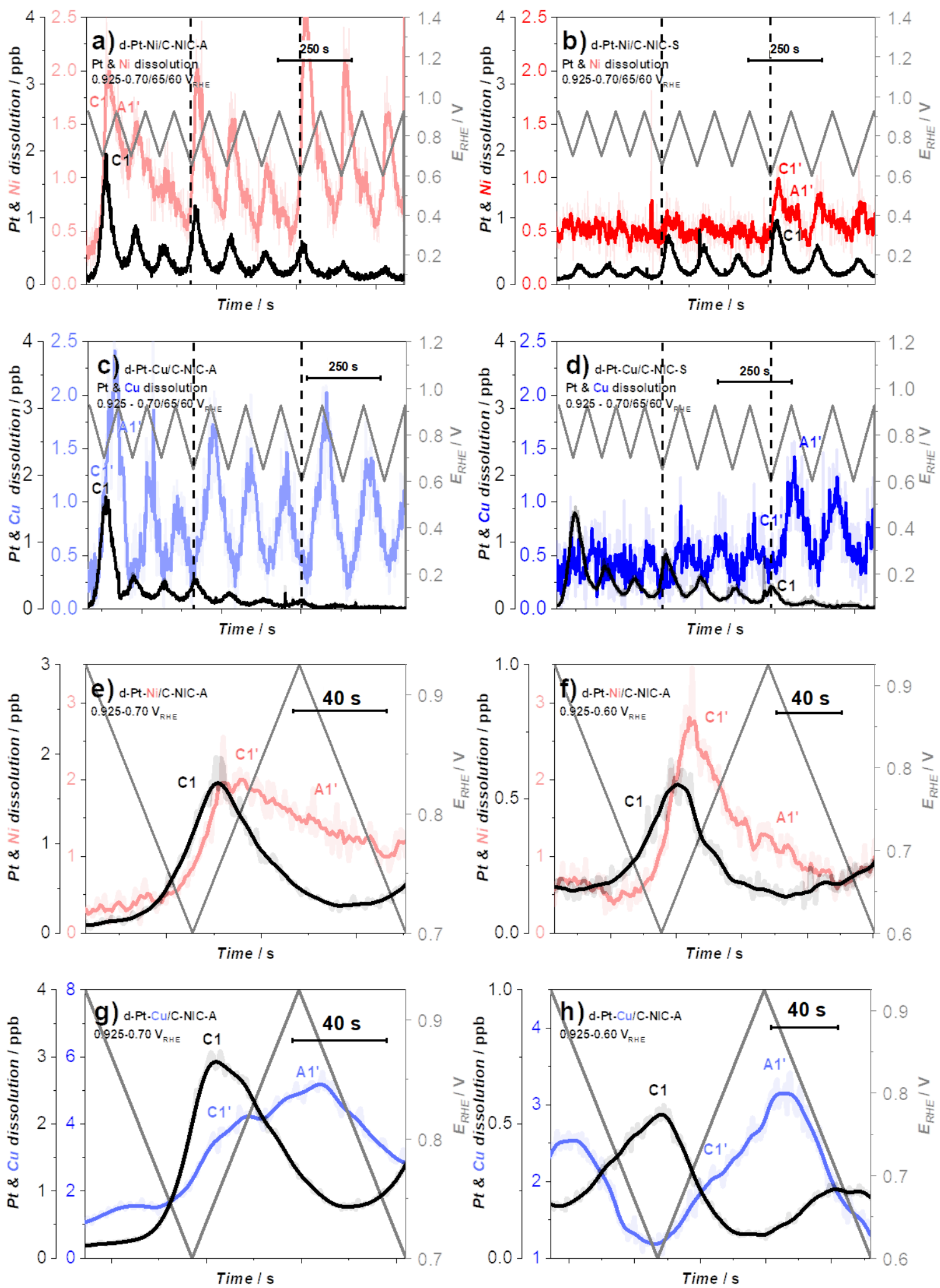

Figure 5. LPL effect $\left(0.925-0 . X V_{R H E} ; X=0.70,0.65\right.$ and $\left.0.60 ; 5 \mathrm{mV} \mathrm{s}^{-1}\right)$ comparison for $A$ and S-activated (a-b) Pt-Ni and (c-d) Pt-Cu catalysts using EFC-ICP-MS. Close-up metal dissolution profiles of $1^{\text {st }}$ and $7^{\text {th }}$ cycle from Figure 5 of the main manuscript for both Aactivated (e-f) Pt-Ni and (g-h) Pt-Cu alloy catalysts at LPLs of 0.7 and 0.6 V. Raw data in (ah) has been smoothed for better visibility. 
In addition to the d-Pt-Ni/C-JM benchmark, we have also tested all four A and Sactivated Pt-alloy catalysts (Figures 5a-d) using the exact same protocol presented in Figure 4a (see also, SI Figure S1 for the II. LPL part of the EFC-ICP-MS protocol). First and foremost, we observe the exact same effect (in other words, increase the less noble metal dissolution upon the decrease of LPL) as in the case of d-Pt-Ni/C-JM benchmark (Figure 4a). Also importantly, analogously to the comparison of metal dissolution in the WPW cycles for the A and S-activated Pt-alloy electrocatalysts (Figures 2e-g), both A-activated catalysts exhibit a dramatically higher amount of less noble metal dissolution (Figures 5a and 5c) in contrast to the S-activated catalysts (Figures $\mathbf{5 b}$ and 5d). We wish to remind the reader, that upon TF-RDE characterization (Figures 2a-d and SI, Figures S8-10), the only noticeable difference between the A and S-activated catalysts for both Pt-Ni and Pt-Cu catalysts was observed in the shift of the CO-electrooxidation peak maximum measured before and after PCA. However, following also the additional comparison of the metal dissolution trends (Figure 2) as well as single-cell performances (Figure 3), it is now rather clear that depending on the choice of the de-alloying (activation) protocol, the electrochemical behavior is influenced substantially.

By focusing on only a single LPL cycle (Figure 5e-h) along with the mechanistic insights gained from the WPW cycles (Figures 2e-h), we can also start to make sense of the mechanisms behind the observed metal dissolution peaks. In both the case of Pt-Cu and Pt-Ni alloys (Figure 5e-h), we see a single peak corresponding to $\mathrm{Pt}$ dissolution. This peak corresponds to the reduction of Pt-oxide and thus, cathodic transient dissolution of $\mathrm{Pt}(\mathrm{C} 1)$. Following the onset of $\mathrm{C} 1 \mathrm{Pt}$ dissolution peak, we observe the onset of the peak corresponding to the dissolution of the less noble metal ( $\mathrm{Cl}^{\prime}$ '). Whereas we do not observe any A1 peak that would correspond to the anodic transient dissolution of $\mathrm{Pt}$, a clear shoulder peak corresponding to the dissolution of the less noble metal A1' is present for both $\mathrm{Pt}-\mathrm{Ni}$ and $\mathrm{Pt}-\mathrm{Cu}$ alloys. Since A1' less noble metal dissolution can only be a direct consequence of the A1 Pt dissolution ${ }^{31,41}$, it is highly likely that the A1 Pt dissolution is simply out of our limit of detection (in contrast to the significantly harsher WPW cycles; Figures 2e-h). Nevertheless, a careful inspection of the observed dissolution profiles reveals many other important messages. For instance, similar differences in the intensities of $\mathrm{A}^{\prime}$ ' and $\mathrm{C} 1$ ' less noble metal dissolutions between Pt-Ni (Figure 5e-f) and Pt-Cu (Figure 5g-h) can be observed as in the case of WPW cycles (Figures 2e-h). In other words, in the case of Pt-Ni alloy, $\mathrm{C} 1$ ' Ni dissolution is dominant in comparison to $\mathrm{A} 1$ ' $\mathrm{Ni}$ dissolution, whereas the situation is reversed in the case of $\mathrm{Pt}-\mathrm{Cu}$ (with $\mathrm{Al}$ ' $\mathrm{Cu}$ dissolution being the dominant peak). This brings us back to the $\mathrm{C} 1 \mathrm{Pt}$ dissolution peak. Our 
evidence suggests that $\mathrm{C} 1$ cathodic $\mathrm{Pt}$ dissolution, as a consequence of oxide-place-exchange is already the dominant Pt-dissolution mechanism at the UPL as low as $0.925 \mathrm{~V}$ (Figures $4 \mathbf{a}$ and 5). This goes in line with the observations made by Ahluwalia and co-workers where $\mathrm{C} 1$ Pt dissolution became dominant only above $0.9 \mathrm{~V}^{65}$. Thus, at UPLs above $0.9 \mathrm{~V}$, the choice of LPL governs the extent of cathodic corrosion of $\mathrm{Pt}^{42}$. Consequently, with more $\mathrm{Pt}$ dissolution, a higher amount of previously protected $\mathrm{M}$ gets exposed to the acidic environment, thus resulting in an increased dissolution of the less noble metal. This is in good agreement with the trends observed during ADT $50 \mathrm{~cm}^{2}$ single-cell tests (Figure 4b), where we can presume that the observed voltage losses at the HCDs can be correlated to the dissolution of $\mathrm{Ni}$ and its consequent interaction with the ionomer ${ }^{32,33}$.

As discussed in this paper, if the upper voltage is controlled at $0.925 \mathrm{~V}$ or lower, the LVL where almost full reduction of the Pt-oxide occurs ${ }^{45}$, such as $0.60 \mathrm{~V}$ (vs RHE) used in this work, can be of particular importance to enable alloy cathodes. Of course, the voltage at which full Pt-oxide reduction occurs depends on the T, $\mathrm{RH}$ and $\mathrm{p}$ used in addition to the composition of the cathode catalyst layer. The observations derived from this work lean towards the hypothesis that Pt-alloys are particularly prone to faster degradation compared pure $\mathrm{Pt}$, if exposed to voltage windows where almost all the Pt-oxide and $\mathrm{OH}_{\mathrm{ad}}$ is removed and grown again using a dynamic profile - leading to the depletion of the less noble metal in the first three or four atomic layers and presence of leached metal ions in the ionomer. The explanation is based on the hypothesis that oxygen diffusion into the subsurface is an important step in the formation of the surface oxide, and for the subsequent Pt dissolution. For a detailed discussion on this topic, the reader is directed to the elegant work by Balbuena and co-workers ${ }^{77}$ on the mechanism of subsurface oxygen formation, surface segregation and Pt dissolution for Pt and Pt-alloys. Considering that the less noble metal composition in the second and third atomic layer of a Pt-alloy is usually in the range of $\mathrm{Pt}: \mathrm{X}(3: 1) \mathrm{X}=\mathrm{Ni}, \mathrm{Co}$ or $\mathrm{Cu}$, from the voltage windows provided in this work, one could easily explain the fast depletion of the less noble metal in the subsurface if exposed to the (0.6-0.925) V voltage window. Dissolution of the less noble metal is influenced by the reactions that occur at the vicinity of the Pt-oxide growth and reduction. On the other hand, if the catalyst surface is left slightly oxidized, such as with the use of narrower voltage windows $(0.70-0.925) \mathrm{V}$ then the depletion of the less noble metal in the subsurface is inhibited under the protocol and conditions used in this work. One would also have to acknowledge that the onset of the oxide growth is shifted to higher voltages/potentials for the case of Pt-alloys compared to $\mathrm{Pt}^{78}$. 
This is of particular relevance for industrial application in MEAs because by preventing the segregation of the less noble metal the negative impact of dissolved metal ions is avoided. This is often overlooked in wet electrochemical cells where dissolved metal ions in the electrolyte do not lead to a decrease in ORR activity. However, in MEAs, it is well known that metal ions can diffuse from the cathode layer to the membrane and back again being the flux of ions back and forwards from the cathode layer to the membrane, proportional to the flux of protons and hence the load. As a consequence proton and oxygen transport can be severely decreased in the presence of dissolved metal ions, which are two of the main reasons for the decrease in performance at high current densities after cycling Pt-alloys, among other factors, as reported by Ramaswamy and co-workers ${ }^{79}$.

\section{CONCLUSIONS}

In summary, to show the critical importance of the catalyst activation we have prepared four de-alloyed (chemically activated) Pt-M ( $\mathrm{M}=\mathrm{Cu}$ or $\mathrm{Ni}$ ) electrocatalysts and compared them with the Pt-Ni alloy catalyst from Johnson Matthey. Namely, both Pt-alloys were subjected to either a 'milder' acetic acid activation protocol or a 'harsher' sulfuric acid activation protocol. Both A- and S-activated analogues were then evaluated using TF-RDE, inline metal dissolution using EFC-ICP-MS methodology as well as tested in the $50 \mathrm{~cm}^{2}$ singlecells at both the hot-wet $\left(80^{\circ} \mathrm{C}, 100 \% \mathrm{RH}\right)$ as well as the hot-dry $\left(80^{\circ} \mathrm{C}, 30 \% \mathrm{RH}\right)$ conditions. In the present study, both A-activated analogues performed significantly worse in $50 \mathrm{~cm}^{2}$ MEAs, experienced a higher amount of less noble metal dissolution and most importantly, exhibited a larger shift in the potential of the CO-electrooxidation peak maximum. Thus, a much simpler and more accessible technique like TF-RDE as a rather precise and very sensitive preliminary indicator (via CO-electrooxidation) that can help distinguish between a 'poorly' or 'adequately' de-alloyed (activated) Pt-alloy electrocatalyst. On the other hand, also following the protocols used in this study, one can gain insights on the chemical activation in relation to the less noble metal dissolution using the EFC-ICP-MS. Furthermore, evaluating Pt-alloy electrocatalysts in single-cells at a lower RH (hot-dry) as well as in air rather than in $\mathrm{O}_{2}$ reveals significantly more information about the performance of Pt-alloy electrocatalyst performance than at high RH (hot-wet). Overall, it is clearly presented that the presence of the less noble metal ions in the CCM is one of the most critical parameters governing the performance of $\mathrm{Pt}$ alloys. 
In the second part of the study, the data generated using both EFC-ICP-MS and ADTs in $50 \mathrm{~cm}^{2}$ single-cells provides clear evidence on the significant importance of the LVL/LPL in relation to the less noble metal dissolution. Thus, better understanding of Pt-oxide formation and reduction in relation to Pt dissolution as well as subsequent dissolution of the less noble metal is crucial to enable the use of Pt-alloy cathodes at HCDs needed for automotive conditions. We show that operating Pt-alloys below $0.7 \mathrm{~V}$ results in a significantly higher degree of less noble metal dissolution and thus, higher voltage losses when using Pt-alloy cathodes in single-cells even at relatively low UVLs/UPLs of $0.925 \mathrm{~V}$. In addition, we have discovered that oxide place exchange responsible for Pt cathodic transient dissolution plays a crucial role in this. Being previously considered as highly important only at UPLs of above 1.1 $\mathrm{V}$, our evidence suggests that it is in-fact the dominant mechanism responsible for the observed performance losses already at operating voltages relevant for operation of Pt-alloys in PEMFCs. Since transient dissolution of the less noble metal is highly connected with the transient dissolution of $\mathrm{Pt}$, following this logic, perhaps operational strategies on the system level ${ }^{9,47}$ as well as modifications inhibiting Pt dissolution and improving the protection of the less noble metal should be of a much larger focus in the future (by for example addition of $\mathrm{Au}$ 68,80-83). Thus, in our opinion, there are still large opportunities not only at investigation of novel chemical activation protocols, but also at the development of highly-stable high metal loaded/high ECSA Pt-alloy electrocatalysts. and also in how system-level operation of Pt-alloy electrocatalysts should be viewed in contrast to traditional $\mathrm{Pt} / \mathrm{C}$ for extending the long-term performance benefits of this still intriguing class of PEMFC electrocatalysts.

\section{Author Contributions}

Matija Gatalo: Conceptualisation, Visualisation, Investigation, Writing - original draft, Writing - review \& editing. Alejandro Martinez Bonastre: Conceptualisation, Visualisation, Investigation, Writing - review \& editing. Leonard-Jean Moriau: Investigation. Harriet Burdett: Investigation. Francisco Ruiz-Zepeda: Investigation. Edwin Hughes: Investigation. Adam Hodgkinson: Investigation. Martin Šala: Investigation. Luka Pavko: Investigation, Writing - review \& editing. Marjan Bele: Investigation. Nejc Hodnik: Resources, Writing - review \& editing, supervision. Jonathan Sharman: Resources, Writing - review \& editing, supervision. Miran Gaberšček: Resources, Writing - review \& editing, supervision. 


\section{Conflicts of interest}

There are no conflicts to declare.

\section{Acknowledgements}

The acknowledgements come at the end of an article after the conclusions and before the notes and references. The authors would like to thank Monik Panchal for the TEM characterisation of the d-Pt-Ni/C-JM benchmark electrocatalyst. The voltage window experiments in MEA included in this work, Figure $4 \mathrm{~b}$, were part of EU funded project INSPIRE. The INSPIRE project has received funding from the FCH 2 JU under grant agreement No 700127. This Joint Undertaking receives support from the European Union's Horizon 2020 research and innovation programme and Hydrogen Europe and N.ERGHY. We would also like to thank the Slovenian research agency (ARRS) programs P2-0393, P1-0034; the projects NC-0007; and European Research Council (ERC) Starting Grant 123STABLE (Grant agreement ID: 852208) and Proof of Concept Grant StableCat (Grant agreement ID: 966654) for funding the study.

\section{REFERENCES}

(1) Gröger, O.; Gasteiger, H. A.; Suchsland, J.-P. Review-Electromobility: Batteries or Fuel Cells? J. Electrochem. Soc. 2015, 162 (14), 2605-2622. https://doi.org/10.1149/2.0211514jes.

(2) Gasteiger, H. A.; Kocha, S. S.; Sompalli, B.; Wagner, F. T. Activity Benchmarks and Requirements for Pt, Pt-Alloy, and Non-Pt Oxygen Reduction Catalysts for PEMFCs. Appl. Catal. B Environ. 2005, $56 \quad$ (1-2), 9-35. https://doi.org/10.1016/j.apcatb.2004.06.021.

(3) https://www.pegasus-pemfc.eu/technical-presentation-of-the-project/ (Date accessed 26.3.2020).

(4) DOE Hydrogen and Fuel Cells Program Record, Department of Energy, USA. https://www.hydrogen.energy.gov/pdfs/17007_fuel_cell_system_cost_2017.pdf (Date accessed: 01.July.2019).

(5) Kongkanand, A.; Mathias, M. F. The Priority and Challenge of High-Power Performance of Low-Platinum Proton-Exchange Membrane Fuel Cells. J. Phys. Chem. Lett. 2016, 7 (7), 1127-1137. https://doi.org/10.1021/acs.jpclett.6b00216. 
(6) Gittleman, C. S.; Kongkanand, A.; Masten, D.; Gu, W. Materials Research and Development Focus Areas for Low Cost Automotive Proton-Exchange Membrane Fuel Cells. Curr. Opin. Electrochem. 2019, 18, 81-89. https://doi.org/10.1016/J.COELEC.2019.10.009.

(7) Jaouen, F.; Proietti, E.; Lefèvre, M.; Chenitz, R.; Dodelet, J.-P.; Wu, G.; Chung, H. T.; Johnston, C. M.; Zelenay, P. Recent Advances in Non-Precious Metal Catalysis for Oxygen-Reduction Reaction in Polymer Electrolyte Fuel Cells. Energy Environ. Sci. 2011, 4 (1), 114-130. https://doi.org/10.1039/C0EE00011F.

(8) Kumar, K.; Dubau, L.; Mermoux, M.; Li, J.; Zitolo, A.; Nelayah, J.; Jaouen, F.; Maillard, F. On the Influence of Oxygen on the Degradation of Fe-N-C Catalysts. Angew. Chemie - Int. Ed. 2020, 59 (8), 3235-3243. https://doi.org/10.1002/anie.201912451.

(9) Kodama, K.; Nagai, T.; Kuwaki, A.; Jinnouchi, R.; Morimoto, Y. Challenges in Applying Highly Active Pt-Based Nanostructured Catalysts for Oxygen Reduction Reactions to Fuel Cell Vehicles. Nat. Nanotechnol. 2021, 16, 140-147.

(10) M.Pourbaix. Atlas of Electrochemical Equilibria in Aqueous Solutions, 2nd Ed; Natl Assn of Corrosion: Houston, TX; 1974.

(11) Banham, D.; Ye, S. Current Status and Future Development of Catalyst Materials and Catalyst Layers for Proton Exchange Membrane Fuel Cells: An Industrial Perspective. ACS Energy Lett. 2017, 2 (3), 629-638. https://doi.org/10.1021/acsenergylett.6b00644.

(12) Escudero-Escribano, M.; Jensen, K. D.; Jensen, A. W. Recent Advances in Bimetallic Electrocatalysts for Oxygen Reduction: Design Principles, Structure-Function Relations and Active Phase Elucidation. Curr. Opin. Electrochem. 2018, 8, 135-146. https://doi.org/10.1016/J.COELEC.2018.04.013.

(13) Huang, X.; Zhao, Z.; Cao, L.; Chen, Y.; Zhu, E.; Lin, Z.; Li, M.; Yan, A.; Zettl, A.; Wang, Y. M.; Duan, X.; Mueller, T.; Huang, Y. High-Performance Transition MetalDoped Pt3Ni Octahedra for Oxygen Reduction Reaction. Science 2015, 348 (6240), 1230-1234. https://doi.org/10.1126/science.aaa8765.

(14) Chen, C.; Kang, Y.; Huo, Z.; Zhu, Z.; Huang, W.; Xin, H. L.; Snyder, J. D.; Li, D.; Herron, J. a; Mavrikakis, M.; Chi, M.; More, K. L.; Li, Y.; Marković, N. M.; Somorjai, G. a; Yang, P.; Stamenković, V. R. Highly Crystalline Multimetallic Nanoframes with Three-Dimensional Electrocatalytic Surfaces. Science 2014, 343 (6177), 1339-1343. https://doi.org/10.1126/science.1249061. 
(15) Choi, S.; Xie, S.; Shao, M.; Odell, J. H.; Lu, N.; Peng, H.-C.; Protsailo, L.; Guerrero, S.; Park, J.; Xia, X.; Wang, J.; Kim, M. J.; Xia, Y. Synthesis and Characterization of 9 Nm $\mathrm{Pt}-\mathrm{Ni}$ Octahedra with a Record High Activity of 3.3 A/MgPt for the Oxygen Reduction Reaction. Nano Lett. 2013, 13, 3420-3425. https://doi.org/10.1021/n1401881z.

(16) Stamenković, V. R.; Fowler, B.; Mun, B. S.; Wang, G.; Ross, P. N.; Lucas, C. a; Marković, N. M. Improved Oxygen Reduction Activity on Pt3Ni(111) via Increased Surface Site Availability. Science 2007, $315 \quad$ (5811), 493-497. https://doi.org/10.1126/science.1135941.

(17) Toda, T.; Igarashi, H.; Uchida, H.; Watanabe, M. Enhancement of the Electroreduction of Oxygen on Pt Alloys with Fe, Ni , and Co. J. Electrochem. Soc. 1999, 146 (10), 3750-3756. https://doi.org/10.1149/1.1392544.

(18) Stonehart, P. Development of Advanced Noble Metal-Alloy Electrocatalysts for Phosphoric Acid Fuel Cells (PAFC). Berichte der Bunsengesellschaft für Phys. Chemie 1990, 913-921. https://doi.org/10.1007/BF01029576.

(19) Stamenković, V.; Mun, B. S.; Mayrhofer, K. J. J.; Ross, P. N.; Marković, N. M.; Rossmeis1, J.; Greeley, J.; Nørskov, J. K. Changing the Activity of Electrocatalysts for Oxygen Reduction by Tuning the Surface Electronic Structure. Angew. Chemie (International ed.) 2006, 45 (18), 2897-2901. https://doi.org/10.1002/anie.200504386.

(20) Strasser, P.; Koh, S.; Anniyev, T.; Greeley, J.; More, K.; Yu, C.; Liu, Z.; Kaya, S.; Nordlund, D.; Ogasawara, H.; Toney, M. F.; Nilsson, A. Lattice-Strain Control of the Activity in Dealloyed Core-Shell Fuel Cell Catalysts. Nat. Chem. 2010, 2 (April), 454460. https://doi.org/10.1038/nchem.623.

(21) Čolić, V.; Bandarenka, A. S. Pt Alloy Electrocatalysts for the Oxygen Reduction Reaction: From Model Surfaces to Nanostructured Systems. ACS Catal. 2016, 6 (8), 5378-5385. https://doi.org/10.1021/acscatal.6b00997.

(22) Calle-Vallejo, F.; Tymoczko, J.; Colic, V.; Vu, Q. H.; Pohl, M. D.; Morgenstern, K.; Loffreda, D.; Sautet, P.; Schuhmann, W.; Bandarenka, A. S. Finding Optimal Surface Sites on Heterogeneous Catalysts by Counting Nearest Neighbors. Science 2015, 350 (6257), 185-189. https://doi.org/10.1126/science.aab3501.

(23) Chattot, R.; Le Bacq, O.; Beermann, V.; Kühl, S.; Herranz, J.; Henning, S.; Kühn, L.; Asset, T.; Guétaz, L.; Renou, G.; Drnec, J.; Bordet, P.; Pasturel, A.; Eychmüller, A.; Schmidt, T. J.; Strasser, P.; Dubau, L.; Maillard, F. Surface Distortion as a Unifying 
Concept and Descriptor in Oxygen Reduction Reaction Electrocatalysis. Nat. Mater. 2018, 17 (9), 827-833. https://doi.org/10.1038/s41563-018-0133-2.

(24) Kongkanand, A.; Wagner, F. High-Activity Dealloyed Catalysts: Https://Www.Hydrogen.Energy.Gov/Pdfs/Review14/Fc087_kongkanand_2014_o.Pdf (Date Accessed 17.3.2021).

(25) Myers, D.; Kariuki, N.; Ahluwalia, R.; Wang, X.; Peng, J.-K. Rationally Designed Catalyst Layers for PEMFC Performance Optimization: Https://Www.Hydrogen.Energy.Gov/Pdfs/Review15/Fc106_myers_2015_o.Pdf (Date Accessed 17.3.2021).

(26) Myers, D.; Kariuki, N.; Ahluwalia, R.; Xiaohua, W.; Cetinbas, C. F.; Peng, J.-K. Rationally Designed Catalyst Layers for PEMFC Performance Optimization: Https://Www.Hydrogen.Energy.Gov/Pdfs/Review16/Fc106_myers_2016_o.Pdf (Date Accessed 17.3.2021).

(27) US Department of Energy (DOE). Multi-Year Research, Development, and Demonstration Plan: 3.4 Fuel Cells: Https://Www.Energy.Gov/Sites/Prod/Files/2017/05/F34/Fcto_myrdd_fuel_cells.Pdf (Date Accessed 17.3.2021); 2017; Vol. 2015. https://doi.org/Department of Energy.

(28) Han, B.; Carlton, C. E.; Kongkanand, A.; Kukreja, R. S.; Theobald, B. R.; Gan, L.; O’Malley, R.; Strasser, P.; Wagner, F. T.; Shao-Horn, Y. Record Activity and Stability of Dealloyed Bimetallic Catalysts for Proton Exchange Membrane Fuel Cells. Energy Environ. Sci. 2015, 8 (1), 258-266. https://doi.org/10.1039/C4EE02144D.

(29) Gatalo, M.; Ruiz-Zepeda, F.; Hodnik, N.; Dražić, G.; Bele, M.; Gaberšček, M. Insights into Thermal Annealing of Highly-Active PtCu3/C Oxygen Reduction Reaction Electrocatalyst: An in-Situ Heating Transmission Electron Microscopy Study. Nano Energy 2019, 63, 103892. https://doi.org/10.1016/j.nanoen.2019.103892.

(30) Gatalo, M.; Moriau, L.; Petek, U.; Ruiz-Zepeda, F.; Šala, M.; Grom, M.; Galun, T.; Jovanovič, P.; Pavlišič, A.; Bele, M.; Hodnik, N.; Gaberšček, M. CO-Assisted Ex-Situ Chemical Activation of $\mathrm{Pt}-\mathrm{Cu} / \mathrm{C}$ Oxygen Reduction Reaction Electrocatalyst. Electrochim. Acta 2019, 306, 377-386. https://doi.org/10.1016/j.electacta.2019.03.153.

(31) Gatalo, M.; Jovanovič, P.; Petek, U.; Šala, M.; Šelih, V. S.; Ruiz-Zepeda, F.; Bele, M.; Hodnik, N.; Gaberšček, M. Comparison of Pt-Cu/C with Benchmark Pt-Co/C: Metal Dissolution and Their Surface Interactions. ACS Appl. Energy Mater. 2019, 2 (5), 3131- 
3141. https://doi.org/10.1021/acsaem.8b02142.

(32) Braaten, J.; Kongkanand, A.; Litster, S. Oxygen Transport Effects of Cobalt Cation Contamination of Ionomer Thin Films in Proton Exchange Membrane Fuel Cells. ECS Trans. 2017, 80 (8), 283-290. https://doi.org/10.1149/08008.0283ecst.

(33) Braaten, J. P.; Xu, X.; Cai, Y.; Kongkanand, A.; Litster, S. Contaminant Cation Effect on Oxygen Transport through the Ionomers of Polymer Electrolyte Membrane Fuel Cells. J. Electrochem. Soc. 2019, $166 \quad$ (16), F1337-F1343. https://doi.org/10.1149/2.0671916jes.

(34) Ahluwalia, R. K.; Wang, X.; Peng, J.-K.; Kariuki, N. N.; Myers, D. J.; Rasouli, S.; Ferreira, P. J.; Yang, Z.; Martinez-Bonastre, A.; Fongalland, D.; Sharman, J. Durability of De-Alloyed Platinum-Nickel Cathode Catalyst in Low Platinum Loading MembraneElectrode Assemblies Subjected to Accelerated Stress Tests. J. Electrochem. Soc. 2018, 165 (6), F3316-F3327. https://doi.org/10.1149/2.0341806jes.

(35) Papadias, D. D.; Ahluwalia, R. K.; Kariuki, N.; Myers, D.; More, K. L.; Cullen, D. A.; Sneed, B. T.; Neyerlin, K. C.; Mukundan, R.; Borup, R. L. Durability of Pt-Co Alloy Polymer Electrolyte Fuel Cell Cathode Catalysts under Accelerated Stress Tests. J. Electrochem. Soc. 2018, 165 (6), F3166-F3177. https://doi.org/10.1149/2.0171806jes.

(36) Strlič, M.; Kolar, J.; Šelih, V.-S.; Kočar, D.; Pihlar, B. A Comparative Study of Several Transition Metals in Fenton-like Reaction System at Circum-neutral pH. Acta Chim. Slov. 2003, 50 (4), 619-632.

(37) Jia, Q.; Ramaker, D. E.; Ziegelbauer, J. M.; Ramaswamy, N.; Halder, A.; Mukerjee, S. Fundamental Aspects of Ad-Metal Dissolution and Contamination in Low and Medium Temperature Fuel Cell Electrocatalysis: A Cu Based Case Study Using In Situ Electrochemical X-Ray Absorption Spectroscopy. J. Phys. Chem. C 2013, 117, $4585-4596$.

(38) Yu, Z.; Zhang, J.; Liu, Z.; Ziegelbauer, J. M.; Xin, H.; Dutta, I.; Muller, D. A.; Wagner, F. T. Comparison between Dealloyed $\mathrm{PtCo} 3$ and $\mathrm{PtCu} 3$ Cathode Catalysts for Proton Exchange Membrane Fuel Cells. J. Phys. Chem. C 2012, 116 (37), 19877-19885. https://doi.org/10.1021/jp306107t.

(39) Zhu, F.; Wu, A.; Luo, L.; Wang, C.; Yang, F.; Wei, G.; Xia, G.; Yin, J.; Zhang, J. The Asymmetric Effects of $\mathrm{Cu} 2+$ Contamination in a Proton Exchange Membrane Fuel Cell (PEMFC). Fuel Cells 2020, 20 (2), 196-202. https://doi.org/10.1002/fuce.201900189. 
(40) Mani, P.; Srivastava, R.; Strasser, P. Dealloyed Pt-Cu Core-Shell Nanoparticle Electrocatalysts for Use in PEM Fuel Cell Cathodes. J. Phys. Chem. C 2008, 112 (7), 2770-2778. https://doi.org/10.1021/jp0776412.

(41) Moriau, L. J.; Hrnjić, A.; Pavlišič, A.; Kamšek, A. R.; Petek, U.; Ruiz-Zepeda, F.; Šala, M.; Pavko, L.; Šelih, V. S.; Bele, M.; Jovanovič, P.; Gatalo, M.; Hodnik, N. Resolving the Dilemma of Nanoparticles' Structure-Property Relationships at the Atomic Level: Case Study of Pt-Based Oxygen Reduction Electrocatalysts. iScience 2021, 102102. https://doi.org/10.1016/j.isci.2021.102102.

(42) Uchimura, M.; Sugawara, S.; Suzuki, Y.; Zhang, J.; Kocha, S. S. Electrocatalyst Durability under Simulated Automotive Drive Cycles. ECS Transactions. ECS 2019, pp 225-234. https://doi.org/10.1149/1.2981858.

(43) Topalov, A. A.; Cherevko, S.; Zeradjanin, A. R.; Meier, J. C.; Katsounaros, I.; Mayrhofer, K. J. J. Towards a Comprehensive Understanding of Platinum Dissolution in Acidic Media. Chem. Sci. 2014, 5, 631-638. https://doi.org/10.1039/C3SC52411F.

(44) Jovanovič, P.; Pavlišič, A.; Šelih, V. S.; Šala, M.; Hodnik, N.; Bele, M.; Hočevar, S.; Gaberšček, M. New Insight into Platinum Dissolution from Nanoparticulate PlatinumBased Electrocatalysts Using Highly Sensitive In Situ Concentration Measurements. Chem. Cat. Chem. 2014, 6 (2), 449-453. https://doi.org/10.1002/cctc.201300936.

(45) Cherevko, S.; Kulyk, N.; Mayrhofer, K. J. J. Durability of Platinum-Based Fuel Cell Electrocatalysts: Dissolution of Bulk and Nanoscale Platinum. Nano Energy 2016, 29, 275-298. https://doi.org/10.1016/j.nanoen.2016.03.005.

(46) Ehelebe, K.; Knöppel, J.; Bierling, M.; Mayerhöfer, B.; Böhm, T.; Kulyk, N.; Thiele, S.; Mayrhofer, K. J. J.; Cherevko, S. Platinum Dissolution in Realistic Fuel Cell Catalyst Layers. Angew. Chemie - Int. Ed. 2021, 60 (16), 8882-8888. https://doi.org/10.1002/anie.202014711.

(47) Yoshida, T.; Kojima, K. Toyota MIRAI Fuel Cell Vehicle and Progress toward a Future Hydrogen Society. Electrochem. Soc. Interface 2015, 24 (2), 45-49. https://doi.org/10.1149/2.F03152if.

(48) Lohse-Busch, H.; Duoba, M.; Stutenberg, K.; Iliev, S.; Kern, M. Technology Assessment of a Fuel Cell Vehicle: 2017 Toyota Mirai; 2018.

(49) Harzer, G. S.; Schwämmlein, J. N.; Damjanović, A. M.; Ghosh, S.; Gasteiger, H. A. Cathode Loading Impact on Voltage Cycling Induced PEMFC Degradation: A Voltage 
Loss Analysis. J. Electrochem. Soc. 2018, 165 (6), F3118-F3131. https://doi.org/10.1149/2.0161806jes.

(50) Gatalo, M.; Bele, M.; Ruiz-Zepeda, F.; Šest, E.; Šala, M.; Kamšek, A. R.; Maselj, N.; Galun, T.; Jovanovič, P.; Hodnik, N.; Gaberšček, M. A Double-Passivation WaterBased Galvanic Displacement Method for Reproducible Gram-Scale Production of High-Performance Platinum-Alloy Electrocatalysts. Angew. Chemie - Int. Ed. 2019, 58 (38), 13266-13270. https://doi.org/10.1002/anie.201903568.

(51) Pavko, L.; Gatalo, M.; Križan, G.; Križan, J.; Ehelebe, K.; Ruiz-Zepeda, F.; Šala, M.; Dražić, G.; Geuß, M.; Kaiser, P.; Bele, M.; Kostelec, M.; Đukić, T.; Van de Velde, N.; Jerman, I.; Cherevko, S.; Hodnik, N.; Genorio, B.; Gaberšček, M. Toward the Continuous Production of Multigram Quantities of Highly Uniform Supported Metallic Nanoparticles and Their Application for Synthesis of Superior Intermetallic Pt-Alloy ORR Electrocatalysts. ACS Appl. Energy Mater. 2021. https://doi.org/10.1021/acsaem.1c02570.

(52) Sasaki, K.; Naohara, H.; Cai, Y.; Choi, Y. M.; Liu, P.; Vukmirović, M. B.; Wang, J. X.; Adzić, R. R. Core-Protected Platinum Monolayer Shell High-Stability Electrocatalysts for Fuel-Cell Cathodes. Angew. Chemie Int. Ed. 2010, 49 (46), 8602-8607. https://doi.org/10.1002/anie.201004287.

(53) van der Vliet, D.; Strmčnik, D.; Wang, C.; Stamenković, V. R.; Marković, N. M.; Koper, M. T. M. On the Importance of Correcting for the Uncompensated Ohmic Resistance in Model Experiments of the Oxygen Reduction Reaction. J. Electroanal. Chem. 2010, 647 (1), 29-34. https://doi.org/10.1016/j.jelechem.2010.05.016.

(54) Bard, A. J. Electrochemical Methods : Fundamentals and Applications / Allen J. Bard, Larry R. Faulkner; Faulkner 1944-, L. R., Ed.; Wiley: New York, 1980.

(55) Mayrhofer, K. J. J.; Strmcnik, D.; Blizanac, B. B.; Stamenkovic, V.; Arenz, M.; Markovic, N. M. Measurement of Oxygen Reduction Activities via the Rotating Disc Electrode Method: From Pt Model Surfaces to Carbon-Supported High Surface Area Catalysts. Electrochim. Acta 2008, 53, 3181-3188. https://doi.org/http://dx.doi.org/10.1016/j.electacta.2007.11.057.

(56) Jovanovič, P.; Petek, U.; Hodnik, N.; Ruiz-Zepeda, F.; Gatalo, M.; Šala, M.; Šelih, V. S.; Fellinger, T. P.; Gaberšček, M. Importance of Non-Intrinsic Platinum Dissolution in Pt/C Composite Fuel Cell Catalysts. Phys. Chem. Chem. Phys. 2017, 19 (32), 21446- 
21452. https://doi.org/10.1039/C7CP03192K.

(57) Pavlišič, A.; Jovanovič, P.; Šelih, V. S.; Šala, M.; Hodnik, N.; Gaberšček, M. Platinum Dissolution and Redeposition from Pt/C Fuel Cell Electrocatalyst at Potential Cycling. J. Electrochem. Soc. $\quad$ 2018, $165 \quad$ (6), $\quad$ F3161-F3165. https://doi.org/10.1149/2.0191806jes.

(58) Pavlišič, A.; Jovanovič, P.; Šelih, V. S.; Šala, M.; Hodnik, N.; Hočevar, S.; Gaberšček, M. The Influence of Chloride Impurities on Pt/C Fuel Cell Catalyst Corrosion. Chem. Commun. 2014, 50 (28), 3732-3734. https://doi.org/10.1039/c4cc00086b.

(59) Jovanovič, P.; Hodnik, N.; Ruiz-Zepeda, F.; Arcon, I.; Jozinović, B.; Zorko, M.; Bele, M.; Šala, M.; Šelih, V. S.; Hocevar, S. B.; Gaberscek, M. Electrochemical Dissolution of Iridium and Iridium Oxide Particles in Acidic Media: Transmission Electron Microscopy, Electrochemical Flow Cell Coupled to Inductively Coupled Plasma Mass Spectrometry and X-Ray Absorption Spectros-Copy Study. J. Am. Chem. Soc. 2017, 139 (36), 12837-12846. https://doi.org/10.1021/jacs.7b08071.

(60) Kocha, S. S. Principles of MEA Preparation. Handbook of Fuel Cells. December 15, 2010. https://doi.org/https://doi.org/10.1002/9780470974001.f303047.

(61) Oezaslan, M.; Hasché, F.; Strasser, P. PtCu3, PtCu and Pt3Cu Alloy Nanoparticle Electrocatalysts for Oxygen Reduction Reaction in Alkaline and Acidic Media. J. Electrochem. Soc. 2012, 159 (4), 444-454. https://doi.org/10.1149/2.106204jes.

(62) Okamoto, H. Ni-Pt (Nickel-Platinum). J. Phase Equilibria Diffus. 2010, 31 (3), 322. https://doi.org/10.1007/s11669-010-9701-0.

(63) Yang, R.; Leisch, J.; Strasser, P.; Toney, M. F. Structure of Dealloyed PtCu3 Thin Films and Catalytic Activity for Oxygen Reduction. Chem. Mater. 2010, 22 (16), 4712-4720. https://doi.org/10.1021/cm101090p.

(64) Meier, J. C.; Galeano, C.; Katsounaros, I.; Witte, J.; Bongard, H. J.; Topalov, A. A.; Baldizzone, C.; Mezzavilla, S.; Schüth, F.; Mayrhofer, K. J. J. Design Criteria for Stable Pt/C Fuel Cell Catalysts. Beilstein J. Nanotechnol. 2014, 5 (1), 44-67. https://doi.org/10.3762/bjnano.5.5.

(65) Ahluwalia, R. K.; Papadias, D. D.; Kariuki, N. N.; Peng, J.-K.; Wang, X.; Tsai, Y.; Graczyk, D. G.; Myers, D. J. Potential Dependence of Pt and Co Dissolution from Platinum-Cobalt Alloy PEFC Catalysts Using Time-Resolved Measurements. J. Electrochem. Soc. 2018, 165 (6), 3024-3035. https://doi.org/10.1149/2.0031806jes. 
(66) Geiger, S.; Cherevko, S.; Mayrhofer, K. J. J. Dissolution of Platinum in Presence of $\begin{array}{llllll}\text { Chloride } & \text { Traces. } & \text { Electrochim. }\end{array}$ https://doi.org/10.1016/j.electacta.2015.03.059.

(67) Pizzutilo, E.; Geiger, S.; Grote, J.-P.; Mingers, A.; Mayrhofer, K. J. J.; Arenz, M.; Cherevko, S. On the Need of Improved Accelerated Degradation Protocols (ADPs): Examination of Platinum Dissolution and Carbon Corrosion in Half-Cell Tests. $J$. Electrochem. Soc. 2016, 163 (14), F1510-F1514. https://doi.org/10.1149/2.0731614jes.

(68) Lopes, P. P.; Strmcnik, D.; Tripkovic, D.; Connell, J. G.; Stamenkovic, V.; Markovic, N. M. Relationships between Atomic Level Surface Structure and Stability/Activity of Platinum Surface Atoms in Aqueous Environments. ACS Catal. 2016, 6 (4), 2536-2544. https://doi.org/10.1021/acscatal.5b02920.

(69) Lopes, P. P.; Tripkovic, D.; Martins, P. F. B. D.; Strmcnik, D.; Ticianelli, E. A.; Stamenkovic, V. R.; Markovic, N. M. Dynamics of Electrochemical Pt Dissolution at Atomic and Molecular Levels. J. Electroanal. Chem. 2018, 819, 123-129. https://doi.org/10.1016/j.jelechem.2017.09.047.

(70) Topalov, A. A.; Katsounaros, I.; Auinger, M.; Cherevko, S.; Meier, J. C.; Klemm, S. O.; Mayrhofer, K. J. J. Dissolution of Platinum: Limits for the Deployment of Electrochemical Energy Conversion? Angew. Chem. Int. Ed. Engl. 2012, 51 (50), 12613-12615. https://doi.org/10.1002/anie.201207256.

(71) Cherevko, S.; Topalov, A. A.; Zeradjanin, A. R.; Keeley, G. P.; Mayrhofer, K. J. J. Temperature-Dependent Dissolution of Polycrystalline Platinum in Sulfuric Acid Electrolyte. Electrocatalysis 2014, 5 (3), 235-240. https://doi.org/10.1007/s12678-0140187-0.

(72) Cherevko, S.; Keeley, G. P.; Geiger, S.; Zeradjanin, A. R.; Hodnik, N.; Kulyk, N.; Mayrhofer, K. J. J. Dissolution of Platinum in the Operational Range of Fuel Cells. ChemElectroChem 2015, 2 (10), 1471-1478. https://doi.org/10.1002/celc.201500098.

(73) Callejas-Tovar, R.; Liao, W.; Martinez de la Hoz, J. M.; Balbuena, P. B. Molecular Dynamics Simulations of Surface Oxidation on $\mathrm{Pt}(111)$ and $\mathrm{Pt} / \mathrm{PtCo} / \mathrm{Pt} 3 \mathrm{Co}(111)$. J. Phys. Chem. C 2011, 115 (10), 4104-4113. https://doi.org/10.1021/jp110436e.

(74) Đukić, T.; Moriau, L. J.; Pavko, L.; Kostelec, M.; Prokop, M.; Ruiz-Zepeda, F.; Šala, M.; Dražić, G.; Gatalo, M.; Hodnik, N. Understanding the Crucial Significance of the Temperature and Potential Window on the Stability of Carbon Supported Pt-Alloy 
Nanoparticles as Oxygen Reduction Reaction Electrocatalysts. ACS Catal. 2021, 101115. https://doi.org/10.1021/acscatal.1c04205.

(75) Durst, J.; Chatenet, M.; Maillard, F. Impact of Metal Cations on the Electrocatalytic Properties of Pt/C Nanoparticles at Multiple Phase Interfaces. Phys. Chem. Chem. Phys. 2012, 14 (37), 13000-13009. https://doi.org/10.1039/c2cp42191g.

(76) Dionigi, F.; Weber, C. C.; Primbs, M.; Gocyla, M.; Bonastre, A. M.; Spöri, C.; Schmies, H.; Hornberger, E.; Kühl, S.; Drnec, J.; Heggen, M.; Sharman, J.; Dunin-Borkowski, R. E.; Strasser, P. Controlling Near-Surface Ni Composition in Octahedral PtNi(Mo) Nanoparticles by Mo Doping for a Highly Active Oxygen Reduction Reaction Catalyst. Nano Lett. 2019, 19 (10), 6876-6885. https://doi.org/10.1021/acs.nanolett.9b02116.

(77) Balbuena, P. B.; Calvo, S. R.; Callejas-Tovar, R.; Gu, Z.; Ramirez-Caballero, G. E.; Hirunsit, P.; Ma, Y. Challenges in the Design of Active and Durable Alloy Nanocatalysts for Fuel Cells BT - Theory and Experiment in Electrocatalysis; Balbuena, P. B., Subramanian, V. R., Eds.; Springer New York: New York, NY, 2010; pp 351-396. https://doi.org/10.1007/978-1-4419-5594-4_9.

(78) Teliska, M.; Murthi, V. S.; Mukerjee, S.; Ramaker, D. E. Correlation of Water Activation, Surface Properties, and Oxygen Reduction Reactivity of Supported Pt-M/C Bimetallic Electrocatalysts Using XAS. J. Electrochem. Soc. 2005, 152 (11), A2159. https://doi.org/10.1149/1.2040949.

(79) Ramaswamy, N.; Kumaraguru, S.; Gu, W.; Kukreja, R. S.; Yu, K.; Groom, D.; Ferreira, P. High-Current Density Durability of $\mathrm{Pt} / \mathrm{C}$ and $\mathrm{PtCo} / \mathrm{C}$ Catalysts at Similar Particle Sizes in PEMFCs. J. Electrochem. Soc. 2021, 168 (2), 24519. https://doi.org/10.1149/1945-7111/abe5ea.

(80) Lopes, P. P.; Li, D.; Lv, H.; Wang, C.; Tripkovic, D.; Zhu, Y.; Schimmenti, R.; Daimon, H.; Kang, Y.; Snyder, J.; Becknell, N.; More, K. L.; Strmcnik, D.; Markovic, N. M.; Mavrikakis, M.; Stamenkovic, V. R. Eliminating Dissolution of Platinum-Based Electrocatalysts at the Atomic Scale. Nat. Mater. 2020. https://doi.org/10.1038/s41563020-0735-3.

(81) Chung, D. Y.; Park, S.; Lee, H.; Kim, H.; Chung, Y.-H.; Yoo, J. M.; Ahn, D.; Yu, S.H.; Lee, K.-S.; Ahmadi, M.; Ju, H.; Abruña, H. D.; Yoo, S. J.; Mun, B. S.; Sung, Y.-E. Activity-Stability Relationship in Au@Pt Nanoparticles for Electrocatalysis. ACS Energy Lett. 2020, 5 (9), 2827-2834. https://doi.org/10.1021/acsenergylett.0c01507. 
(82) Kodama, K.; Jinnouchi, R.; Takahashi, N.; Murata, H.; Morimoto, Y. Activities and Stabilities of Au-Modified Stepped-Pt Single-Crystal Electrodes as Model Cathode Catalysts in Polymer Electrolyte Fuel Cells. J. Am. Chem. Soc. 2016, 138 (12), 41944200. https://doi.org/10.1021/jacs.6b00359.

(83) Gatalo, M.; Jovanovič, P.; Polymeros, G.; Grote, J.-P.; Pavlišič, A.; Ruiz- Zepeda, F.; Šelih, V. S.; Šala, M.; Hočevar, S.; Bele, M.; Mayrhofer, K. J. J.; Hodnik, N.; Gaberšček, M. Positive Effect of Surface Doping with $\mathrm{Au}$ on the Stability of Pt-Based Electrocatalysts. ACS Catal. 2016, 6 (3). https://doi.org/10.1021/acscatal.5b02883. 